Article

\title{
Candida tropicalis as a Promising Oleaginous Yeast for Olive Mill Wastewater Bioconversion
}

\author{
Bruna Dias ${ }^{\dagger}$, Marlene Lopes ${ }^{\dagger}$, Renata Ramôa, Ana S. Pereira and Isabel Belo * \\ Centre of Biological Engineering, University of Minho, 4710-057 Braga, Portugal; brunafsdias@hotmail.com (B.D.); \\ marlenelopes@deb.uminho.pt (M.L.); renatafilipa14@hotmail.com (R.R.); anasofiasp@ceb.uminho.pt (A.S.P.) \\ * Correspondence: ibelo@deb.uminho.pt \\ + Both authors contributed equally to this work.
}

Citation: Dias, B.; Lopes, M.; Ramôa,

R.; Pereira, A.S; Belo, I. Candida tropicalis as a Promising Oleaginous Yeast for Olive Mill Wastewater

Bioconversion. Energies 2021, 14, 640 . https://doi.org/10.3390/en14030640

Academic Editors: Diego Luna and Antonio Zuorro

Received: 23 December 2020

Accepted: 22 January 2021

Published: 27 January 2021

Publisher's Note: MDPI stays neutral with regard to jurisdictional claims in published maps and institutional affiliations.

Copyright: (c) 2021 by the authors. Licensee MDPI, Basel, Switzerland. This article is an open access article distributed under the terms and conditions of the Creative Commons Attribution (CC BY) license (https:// creativecommons.org/licenses/by/ $4.0 /)$.

\begin{abstract}
Olive mill wastewater (OMW), which is generated during olive oil production, has detrimental effects on the environment due to its high organic load and phenolic compounds content. OMW is difficult to biodegrade, but represents a valuable resource of nutrients for microbial growth. In this study, yeast strains were screened for their growth on phenolic compounds usually found in OMW and responsible for antimicrobial effects. Candida tropicalis ATCC 750 demonstrated an extraordinary capacity to grow in phenolics and was chosen for further experiments with OMW-based medium. The effects of nitrogen supplementation, the $\mathrm{pH}$, and the stirring rate on cellular growth, OMW-components consumption, and added-value compounds production were studied in batch cultures in Erlenmeyer flasks and in a bioreactor. Candida tropicalis was able to reduce $68 \%$ of the organic load (chemical oxygen demand) and 39\% of the total phenols of OMW in optimized conditions in bioreactor experiments, producing lipase $\left(203 \mathrm{U} \cdot \mathrm{L}^{-1}\right)$ and protease $\left(1105 \mathrm{U} \cdot \mathrm{L}^{-1}\right)$. Moreover, intracellular lipids were accumulated, most significantly under nitrogen-limited conditions, which is common in this type of wastewater. The high potential of $C$. tropicalis to detoxify OMW and produce added-value compounds from it makes this process an alternative approach to other conventional processes of OMW treatment.
\end{abstract}

Keywords: olive mill wastewater; phenolic compounds; Candida tropicalis; microbial lipids; lipase; protease

\section{Introduction}

The olive oil production industry is an important and traditional agro-industry in Mediterranean countries, accounting for $97 \%$ of the world's production of olive oil [1]. In 2018/2019, the world's largest olive oil producers were Spain, Morocco, Turkey, Greece, Italy, Tunisia, and Portugal [2]. Three systems are used worldwide to extract olive oil, namely, the traditional press system, the three-phase centrifugation system, and the twophase centrifugation system. The three-phase process generates huge amounts of olive mill wastewater (OMW), with a volume that is three-fold higher than the press system and eight-fold larger than the two-phase process [1,3]. It is estimated that approximately 10-30 million $\mathrm{m}^{3}$ of OMW are produced worldwide per year [4].

OMW is characterized by an intense dark brown color, strong acidic smell, high conductivity, low $\mathrm{pH}$, high chemical and biological oxygen demand, and heterogeneous composition. The large diversity of components found in OMW (polysaccharides, sugars, polyalcohols, tannins, proteins, organic acids, lipids, and water-soluble phenols and polyphenols) hampers their efficient treatment and their disposal is a critical environmental problem. In addition, the dark color and phytotoxic and antimicrobial effects of OMW have been attributed to the phenolic compounds that are found in various concentrations in the wastewater $[1,5]$. The OMW phenolic content $\left(0.4-18 \mathrm{~g} \cdot \mathrm{L}^{-1}\right)$ shows great variability and depends on several factors, such as the type of olive, stage of maturity, and extraction system. More than 30 different phenolic compounds have been identified in OMW, 
namely, monocyclic aromatic molecules (e.g., hydroxytyrosol, tyrosol, catechol, and caffeic acid, among others) and compounds with a high molecular mass (e.g., oleuropein, flavonoids, etc.). Hydroxytyrosol and tyrosol stand out due to their abundance in OMW and antioxidant activity. Flavonoids, anthocyanins, tyrosol, hydroxytyrosol, oleanolic acid, and maslinic acid are considered natural antioxidants of considerable commercial and economic interest $[3,6]$. The recovery of phenolic compounds can provide not only an economic opportunity (in food, cosmetic, detergent, and pharmaceutical industries), but also reduce the environmental charge of the wastewater. However, it is hardly applicable at the industrial level due to its operating costs $[3,6]$.

Several methods have been developed and applied for OMW treatment, including physicochemical technologies (e.g., extraction, incineration, sedimentation, adsorption, distillation, evaporation, coagulation, flocculation, reverse osmosis, cryogenesis, membrane processes, and oxidation processes) and biological methods (e.g., composting, enzymatic treatments, and aerobic and anaerobic biodegradation by microorganisms) [1,3]. Compared to physicochemical methods, a biological approach is currently preferred because it is environmentally friendly and reliable, involves lower operation costs, and provides an opportunity for the complete degradation of toxic products. Furthermore, the microbial treatments have the advantage of converting pollutant compounds of OMW into valuable products of industrial interest (e.g., organic acids, biopolymers, enzymes, ethanol, singlecell protein, microbial lipids, and methane, among others) [1]. Therefore, the current OMW treatment strategy is a combination of detoxifying OMW and utilizing it, at the same time, for producing valuable by-products and bioenergy [6].

In the literature, there are several studies regarding the microbial degradation of OMW in aerobic conditions, including bacteria, fungi, algae, and yeasts $[1,7,8]$. In general, bacteria are not able to assimilate the complex polyphenols responsible for the dark coloration of OMW. The use of filamentous fungi on a large scale is considered limited by the difficulty of achieving a homogeneous culture owing to the formation of fungal pellets and other aggregations and the requirement of long-lasting fermentation cycles of no less than 2 weeks [9]. To overcome some of these limitations, yeasts have appeared as promising microorganisms for valorizing OMW, since they are more adaptable and resistant to high concentrations of phenolics and the low $\mathrm{pH}$ of OMW. Some studies have reported that yeasts are good candidates for OMW treatment because they are able to grow in lipidic-substrates, consume the organic material, degrade polyphenols, and produce biomass and other valuable products, such as lipids, lipase, citric acid, ethanol, and mannitol [10-12]. Nevertheless, the efficiency of organic and phenolic content reduction, as well as metabolite production from OMW, is strongly dependent on the yeast strain and operational conditions [13-15].

Therefore, the search for new yeast strains that are able to grow in OMW and detoxify this wastewater, with the concomitant production of added-value compounds, is of the utmost interest for the chemical and bioenergy industry. Therefore, the first aim of this study was to screen and select yeast strains able to grow in phenolic compounds found in OMW. Thereafter, the performance of the selected strain-Candida tropicalis ATCC 750-was evaluated in OMW-based medium, monitoring phenolics, reducing sugars, and chemical oxygen demand (COD) reduction. Batch cultures in an Erlenmeyer flask were carried out to assess the effect of the OMW load and nitrogen supplementation on yeast behavior. Effects of environmental factors, such as the $\mathrm{pH}$ and stirring rate, on medium component consumption and metabolic compounds production (e.g., microbial oils, lipase, and protease) were studied in a lab-scale bioreactor. Our purpose was to develop a biotechnological process for OMW detoxification, evaluating its potential to be used as raw material for yeast growth and added-value compounds production, such as enzymes and microbial lipids that can replace vegetable oils in biodiesel production. 


\section{Materials and Methods}

\subsection{Yeast Strains and Maintenance}

Candida tropicalis ATCC 750, Candida utilis CBS 621, Candida rugosa PYCC 3238, Candida cylindracea CBS 7869, Yarrowia lipolytica IMUFRJ 50682, Yarrowia lipolytica CBS 2073, Yarrowia lipolytica NYCC 1026, Yarrowia lipolytica CBS 2075, Yarrowia lipolytica W29, and Pichia pastoris CBS 2612 were maintained on Yeast Peptone Dextrose (YPD) agar medium (20 g. $\mathrm{L}^{-1}$ glucose, $20 \mathrm{~g} \cdot \mathrm{L}^{-1}$ peptone, $10 \mathrm{~g} \cdot \mathrm{L}^{-1}$ yeast extract, and $20 \mathrm{~g} \cdot \mathrm{L}^{-1}$ agar) at $4{ }^{\circ} \mathrm{C}$ for a maximum of two weeks.

\subsection{Screening of Yeast Strains' Ability to Grow on Phenolic Compounds}

The ability of ten yeast strains, mentioned above, to grow on solid medium with catechol, tyrosol, and phenol as a carbon source was initially evaluated in Petri plate experiments. For each yeast strain, cells were pre-grown overnight in YPD medium. This pre-inoculum was diluted to obtain a yeast culture with an optical density of 0.6 and successive dilutions (up to $10^{-3}$ ) from this culture were prepared in $\mathrm{NaCl} 0.9 \%$. A total of $30 \mu \mathrm{L}$ of each dilution was inoculated on an agar plate containing $0.5 \mathrm{~g} \cdot \mathrm{L}^{-1}$ of each phenolic compound, $6.7 \mathrm{~g} \cdot \mathrm{L}^{-1}$ yeast nitrogen base (YNB) without amino acids and with ammonium sulfate, and $20 \mathrm{~g} \cdot \mathrm{L}^{-1}$ agar. Two control experiments were also carried out: (1) Glucose as the carbon source and (2) no addition of any carbon source (YNB medium). Petri plates inoculated with different yeast strains were placed in an inverted manner in a static incubator oven at $30^{\circ} \mathrm{C}$ for $48 \mathrm{~h}$. Cellular growth in each carbon source was evaluated visually by the appearance of colonies.

\subsection{6-Well Microplate Experiments with Phenolic Compounds}

Six yeast strains (Pichia pastoris CBS 2612, Candida utilis CBS 621, Candida cylindracea CBS 7869, Candida tropicalis ATCC 750, Yarrowia lipolytica W29, and Yarrowia lipolytica CBS 2075), selected from Petri plate experiments, were evaluated for their ability to grow in liquid medium with catechol, tyrosol, and phenol as the carbon source in small scale 96-well microplate experiments. Each well of the microplate was inoculated with $30 \mu \mathrm{L}$ of yeast culture pre-grown overnight in YPD medium, $240 \mu \mathrm{L}$ of YNB without amino acids and with ammonium sulfate (final concentration $6.7 \mathrm{~g} \cdot \mathrm{L}^{-1}$ ), and $30 \mu \mathrm{L}$ of phenolic compounds (final concentration of $1 \mathrm{~g} \cdot \mathrm{L}^{-1}$ ). Two control experiments were also carried out: (1) No inoculation of medium to reduce the interference of color development in absorbance due to the oxidation of phenolic compounds and (2) no addition of any phenolic compound (YNB medium). The cultures in microplates were incubated at $30{ }^{\circ} \mathrm{C}$ for $48 \mathrm{~h}$. Cellular growth on each carbon source was assessed by the optical density $(\lambda=600 \mathrm{~nm})$ at the beginning and end of the experiments.

\subsection{Candida tropicalis ATCC 750 Growth in OMW-Based Medium}

The ability of $C$. tropicalis ATCC 750 to grow in different concentrations of OMW was firstly evaluated in batch cultures, carried out in 96-well microplates for $48 \mathrm{~h}$. In total, $30 \mu \mathrm{L}$ of cell suspension pre-grown overnight in YPD medium was transferred to each microplate well, composed of sterilized OMW $(5-50 \%, v / v)$ and $6.7 \mathrm{~g} \cdot \mathrm{L}^{-1} \mathrm{YNB}$ without amino acids and with ammonium sulfate. In order to reduce the interference of color development due to the oxidation of phenolic compounds of OMW, two control experiments were carried out: (1) YNB medium inoculated with C. tropicalis ATCC 750 and (2) OMW-based medium not inoculated. The 96-well microplates were incubated for $48 \mathrm{~h}$ at $30^{\circ} \mathrm{C}$ and cellular growth was assessed by the optical density $(\lambda=600 \mathrm{~nm})$ at the beginning and end of the experiments.

\subsection{Erlenmeyer Flask Experiments with Nitrogen Supplementation}

Batch cultures with C. tropicalis ATCC 750 were performed in 250-mL Erlenmeyer flasks filled with $100 \mathrm{~mL}$ of diluted OMW $(50 \%, v / v)$ and YNB without amino acids to study the effect of nitrogen supplementation on yeast growth, total phenols, and COD 
degradation and biocompounds production. Several nitrogen sources-ammonium chloride, ammonium sulfate, and urea-and three different OMW samples were used in these experiments. The same amount of nitrogen $\left(1.06 \mathrm{~g} \cdot \mathrm{L}^{-1}\right)$ of each source was added to OMW. Experiments, without nitrogen supplementation and with YNB without amino acids and without ammonium sulfate, were carried out using OMW-2 and OMW-3. Candida tropicalis cells were pre-grown overnight in YPD medium, centrifuged, and resuspended in OMWbased medium at an initial biomass concentration of $0.5 \mathrm{~g} \cdot \mathrm{L}^{-1}$. Erlenmeyer flasks were placed in an orbital incubator oven at $30^{\circ} \mathrm{C}$ and $200 \mathrm{rpm}$ (rotations per minute) for 6 days.

\subsection{Bioreactor Experiments}

Candida tropicalis ATCC 750 batch experiments were carried out using a 2-L bioreactor (BIOLAB, B. Braun, Germany), filled with $0.5 \mathrm{~L}$ of culture medium (50\% diluted OMW$3,1.7 \mathrm{~g} \cdot \mathrm{L}^{-1} \mathrm{YNB}$ without amino acids and without ammonium sulfate, and $4.05 \mathrm{~g} \cdot \mathrm{L}^{-1}$ ammonium chloride). Yeast cells were pre-grown overnight in YPD medium, centrifuged, and resuspended in culture medium at an initial biomass concentration of $0.5 \mathrm{~g} \cdot \mathrm{L}^{-1}$. Two different $\mathrm{pH}$ values (5 and 7) and agitation rates (200 and $500 \mathrm{rpm}$ ) were tested at $30^{\circ} \mathrm{C}$ and a $1 \mathrm{vvm}$ (volume of air per volume of medium per minute) aeration rate for 6 days. The $\mathrm{pH}$ was monitored through the cultivation time with a probe (405-DPAS-SC-K8S, Mettler Toledo, Greisensee, Switzerland) and maintained at 5.5 or 7 by the addition of $\mathrm{HCl} 2 \mathrm{M}$ and $\mathrm{NaOH} 2 \mathrm{M}$. Dissolved oxygen in the culture medium was measured with a polarographic probe (12/220 T-type, Mettler Toledo, Greisensee, Switzerland) and the respective meter (type 170).

\subsection{Analytical Methods}

At appropriate intervals, culture samples were collected from Erlenmeyer flasks and bioreactor for quantification of the cellular concentration, reducing sugars, total phenols, chemical oxygen demand (COD), total organic carbon (TOC), total nitrogen (TN), lipase activity, protease activity, and microbial lipids and their composition of long chain fatty acids (LCFA).

The cellular concentration was quantified by cell counting using a Neubauer counting chamber (Paul Marienfeld GmbH \& Co, Lauda-Königshofen, Germany) in a binocular bright-field microscope (Leica DM 750, Wetzlar, Germany) and converted to the cell dry weight $\left(\mathrm{g} \cdot \mathrm{L}^{-1}\right)$ by a calibration curve.

Reducing sugars were measured by the 3,5-dinitrosalicylic acid (DNS) method [16]. Total phenols were assessed by the Folin-Ciocalteau method (Commission Regulation (EEC) No. 2676/90) using gallic acid as the standard. COD, TOC, and TN were measured by the test kits LCK 914, LCK 387, and LCK 338 (Lange, Hach, Germany), respectively.

Extracellular lipase activity was measured in the culture supernatant by a spectrophotometric assay method using $p$-nitrophenyl butyrate $1 \mathrm{mM}$ as the substrate [17]. The enzymatic reaction was followed by the measurement of absorbance $(\lambda=410 \mathrm{~nm})$ every $30 \mathrm{~s}$ for $10 \mathrm{~min}$ on a microtiter plate (Multiskan Sky, Thermo Fisher Scientific, Waltham, MA, USA) at $37^{\circ} \mathrm{C}$. Enzyme activity was calculated by linear regression of absorbance vs. time, using the molar extinction coefficient of $p$-nitrophenol $\left(3.252 \mathrm{mM}^{-1}\right)$. One unit of lipase activity was defined as the amount of enzyme that produces $1 \mu \mathrm{mol}$ of $p$-nitrophenol per minute under the assay conditions.

Extracellular protease activity was quantified using azocasein $0.5 \%(w / v)$ dissolved in sodium acetate buffer $50 \mathrm{mM}\left(\mathrm{pH}\right.$ ) ) as the substrate at $37^{\circ} \mathrm{C}$ for $40 \mathrm{~min}$ [17]. One unit of protease activity was defined as the amount of enzyme that causes an increase of 0.01 of absorbance comparative to the blank per minute under assay conditions.

Microbial lipids were extracted from lyophilized cells $(10 \mathrm{mg})$ with a mixture $(2 \mathrm{~mL})$ of methanol and chloroform $(1: 1, v / v)$ and quantified by the phospho-vanillin colorimetric method, according to Lopes et al. [17]. After vortex-mixing the extraction mixture for $3 \mathrm{~min}$ to cell disruption, a $250 \mu \mathrm{L}$ aliquot was transferred to a test tube and heated to $100{ }^{\circ} \mathrm{C}$. After evaporation of the solvents, $100 \mu \mathrm{L}$ of pure sulfuric acid was added to each tube, which was 
vortexed and heated at $100{ }^{\circ} \mathrm{C}$ for $15 \mathrm{~min}$. The tubes were left to cool to room temperature and $2.4 \mathrm{~mL}$ of phospho-vanillin reagent $\left(1.2 \mathrm{~g} \cdot \mathrm{L}^{-1}\right.$ vanillin dissolved in orthophosphoric acid $85 \%$ ) was then added. The mixture was vortexed and the absorbance at $490 \mathrm{~nm}$ was measured in a microplate reader (Multiskan Sky, Thermo Fisher Scientific, Waltham, MA, USA) after $15 \mathrm{~min}$. The absorbance was converted to the lipid concentration $\left(\mathrm{g} \cdot \mathrm{L}^{-1}\right)$ by a calibration curve (olive oil dissolved in acetone was used as the standard).

The fatty acid composition of microbial lipids was analyzed after extraction with chloroform and methylation with a mixture of methanol acidified with sulfuric acid (15:85, v/v) [17]. Using gas chromatography (CP-3800 gas chromatograph, Varian Inc., Palo Alto, California, USA), fitted with a flame ionization detector and TRACSIL TR-WAX capillary column (30 m $\times 0.25 \mathrm{~mm} \times 0.25 \mu \mathrm{m}$, Teknokroma, Barcelona, Spain), the fatty acid methyl esters (FAME) in organic phase were quantified, according to the protocol described by Lopes et al. [17]. Heptadecanoic acid (C17:0) was used as the internal standard. The relative amount of each LCFA (\%) was defined by the ratio between its concentration $\left(\mathrm{g} \cdot \mathrm{L}^{-1}\right)$ and the sum of the concentrations of all LCFA analyzed.

\subsection{Statistical Analysis}

Tukey's test was performed in GraphPad Prism (version 6) to evaluate the statistical differences between the results of the experiments.

Principal component analysis (PCA) was conducted with XLSTAT (Addinsoft for Microsoft Excel) to assess the influence of the OMW composition on the parameters analyzed.

\section{Results and Discussion}

\subsection{OMW Characterization}

OMW used in this work was collected from olive mills from the north of Portugal. All OMW samples contained high levels of organic load, expressed as the COD content, and a high total phenolics concentration (Table 1), comparable to others reported in the literature $[14,18]$. However, OMW-1 is more highly charged in organic matter than OMW-2 and OMW-3 $(p<0.05)$, mainly due to its higher content of sugars and phenols. On the other hand, OMW-1 and OMW-2 are poorer effluents in terms of the nitrogen component. They have $\mathrm{C} / \mathrm{N}$ ratios equal to 163 and 132, respectively, which are higher than the value for OMW-3-24. This composition makes them toxic effluents and a proper treatment is needed before their discharge. However, OMW has considerable amounts of sugars, justifying its use as a substrate for microbial growth despite the low nitrogen content $\left(<1 \mathrm{~g} \cdot \mathrm{L}^{-1}\right)$.

Table 1. Main characteristics of olive mill wastewater (OMW). Data are the average \pm standard deviation of two independent measurements. Values followed by the same letter in each row do not present statistically significant differences $(p \leq 0.05)$.

\begin{tabular}{cccc}
\hline Parameter & OMW-1 & OMW-2 & OMW-3 \\
\hline pH & $5.03 \pm 0.01^{\mathrm{a}}$ & $4.83 \pm 0.02^{\mathrm{b}}$ & $4.94 \pm 0.09^{\mathrm{a}, \mathrm{b}}$ \\
COD $\left(\mathrm{g} \cdot \mathrm{L}^{-1}\right)$ & $108.7 \pm 0.4^{\mathrm{a}}$ & $51.3 \pm 1.3^{\mathrm{b}}$ & $36.7^{\mathrm{b}} \pm 3.0^{\mathrm{c}}$ \\
Total Nitrogen $\left(\mathrm{mg} \cdot \mathrm{L}^{-1}\right)$ & $285.7 \pm 0.2^{\mathrm{a}}$ & $152.4 \pm 2.3^{\mathrm{b}}$ & $626.8^{6} \pm .2^{\mathrm{c}}$ \\
Total Phenols $\left(\mathrm{g} \cdot \mathrm{L}^{-1}\right)$ & $4.83 \pm 0.05^{\mathrm{a}}$ & $2.6 \pm 0.1^{\mathrm{b}}$ & $1.8^{\mathrm{b}} \pm 0.1^{\mathrm{c}}$ \\
Reducing Sugars $\left(\mathrm{g} \cdot \mathrm{L}^{-1}\right)$ & $36.3 \pm 0.3^{\mathrm{a}}$ & $13.2 \pm 0.2^{\mathrm{b}}$ & $10.1^{\mathrm{c}} \pm .05^{\mathrm{c}}$ \\
TOC $\left(\mathrm{g} \cdot \mathrm{L}^{-1}\right)$ & $46.6 \pm 1.0^{\mathrm{a}}$ & $20.1 \pm 0.3^{\mathrm{b}}$ & $15.0 \pm 0.9^{\mathrm{c}}$ \\
\hline
\end{tabular}

\subsection{Screening of Yeast Strains' Ability to Grow on Phenolic Compounds}

The ability of yeast species and strains, belonging to Yarrowia, Candida, and Pichia genera, to metabolize phenolic compounds as the only source of carbon and energy was reported by Gonçalves et al. [19] and Karimi and Hassanshahian [20]. However, more work on the screening of new yeast strains with a high capacity to assimilate phenolic compounds is still needed. Therefore, a total of 10 yeast strains were firstly evaluated for 
their ability to grow on different phenolic compounds (catechol, tyrosol, and phenol) on agar plates (Table 2).

Table 2. Yeast growth on agar plates with different phenolic compounds. Glucose and YNB (no carbon source) were used as control experiments.

\begin{tabular}{cccccc}
\hline Yeast Strains & Glucose & Phenol & Catechol & Tyrosol & YNB \\
\hline Pichia pastoris CBS 2612 & ++++ & - & + & ++ & ++ \\
Candida utilis CBS 621 & ++++ & - & + & + & + \\
Candida rugosa PYCC 3238 & ++++ & - & - & + & - \\
Candida cylindracea CBS 7869 & ++++ & + & - & ++ & ++ \\
Candida tropicalis ATCC 750 & ++++ & ++++ & ++++ & ++++ & +++ \\
Yarrowia lipolytica IMUFR 50682 & ++++ & - & - & ++ & ++ \\
Yarrowia lipolytica W29 & ++++ & - & - & + & + \\
Yarrowia lipolytica CBS 2073 & ++++ & - & - & + & + \\
Yarrowia lipolytica NCYC 1026 & +++ & - & - & + & + \\
Yarrowia lipolytica CBS 2075 & ++++ & + & - & ++ & ++ \\
\hline
\end{tabular}

$\overline{++++, \text { growth up to } 10^{-3} \text { dilution; }+++ \text {, growth up to } 10^{-2} \text { dilution; }++ \text {, growth up to } 10^{-1} \text { dilution; }+ \text {, growth }}$ with no dilution; and -, no growth.

As expected for these yeast strains, all grew well with glucose as the carbon source, even in the highest dilutions. In general, with the exception of C. rugosa PYCC 3238, all yeast strains grew without a carbon source (YNB medium), because this medium contains nitrogen, vitamins, salts, and growth factors. However, yeast growth in YNB medium was lower than that obtained with glucose.

Among the phenolic compounds tested, it was observed that yeast growth was higher in tyrosol, followed by catechol and phenol. In fact, seven yeast strains did not grow in phenol-based medium-Pichia pastoris, Candida utilis, Candida rugosa, and four Yarrowia lipolytica strains. Yeast growth was not detected in catechol-based medium for Yarrowia lipolytica strains, Candida cylindracea, and Candida rugosa. In contrast, all yeast strains grew on tyrosol-based medium. These results are in accordance with those reported by Gonçalves et al. [19], which demonstrated that catechol was the most inhibitory for C. rugosa CBS 2275 and Y. lipolytica W29 growth, while tyrosol had no inhibitory effect. However, Vatsal et al. [21] reported that Y. lipolytica NCIM 3589 was able to grow in several concentrations of phenol and catechol (0.5-5 mM).

Candida tropicalis ATCC 750 stood out as the yeast strain with a greater ability to grow in tyrosol, catechol, and phenol. Furthermore, yeast growth in all phenolic compounds tested was similar to that obtained in glucose.

Taking into account the preliminary results obtained for the agar plate, Candida tropicalis ATCC 750, Candida cylindracea CBS 7869, Pichia pastoris CBS 2612, Yarrowia lipolytica CBS 2075, Candida utilis CBS 621, and Yarrowia lipolytica W29 were selected for the next screening performed in liquid medium in 96-well microplates (Table 3). As occurred in Petri plate experiments, Candida tropicalis ATCC 750 stood out for its ability to grow in catechol, tyrosol, and phenol liquid medium. In fact, an approximate three-fold improvement in the final biomass was obtained in phenolic medium compared to the control (YNB). These results are in accordance with others found in the literature, reporting the ability of $C$. tropicalis CC1 [22] and C. tropicalis NPD1401 [23] to grow in phenol.

All phenolic compounds studied had an inhibitory effect on P. pastoris CBS 2612 metabolism and no cellular growth was observed. To the best of our knowledge, there are no reports in the literature about the effect of phenolic compounds on the metabolism and cellular growth of non-genetically modified P. pastoris strains. Candida utilis CBS 621 growth was inhibited by the presence of tyrosol, but considerable growth was observed in phenol-based medium compared to the control. Giavasis and Petrotos [15] concluded that phenolic compounds have an inhibitory effect on C. utilis DSM-2361 growth, since the values of the cellular concentration were lower in OMW compared to dephenolized OMW. Candida cylindracea CBS 7869 growth was inhibited by the presence of catechol and phenol. 
However, other authors have reported the ability of $C$. cylindracea strains to use phenolic compounds as a carbon source and grow well in phenolic-rich effluents [19,24].

Table 3. Cellular growth of several yeast strains in liquid phenolic compound-based media and YNB (control) evaluated by the difference between the optical density $(\lambda=600 \mathrm{~nm})$ at the end $(48 \mathrm{~h})$ and beginning $(0 \mathrm{~h})$ of the experiments. Data are the average \pm standard deviation of three independent replicates. Values followed by the same letter in each row do not present statistically significant differences ( $p \leq 0.05)$.

\begin{tabular}{|c|c|c|c|c|}
\hline \multirow{2}{*}{ Yeast Species } & \multicolumn{4}{|c|}{$\mathrm{Abs}_{48 \mathrm{~h}}-\mathrm{Abs}_{0 \mathrm{~h}}$} \\
\hline & YNB & Catechol & Tyrosol & Phenol \\
\hline Pichia pastoris CBS 2612 & $0.15 \pm 0.01$ & ND & ND & ND \\
\hline Candida utilis CBS 621 & $0.12 \pm 0.01^{a}$ & $0.10 \pm 0.02^{\mathrm{a}}$ & ND & $0.24 \pm 0.03^{b}$ \\
\hline Candida cylindracea CBS 7869 & $0.29 \pm 0.02^{a}$ & ND & $0.38 \pm 0.04^{\mathrm{a}}$ & ND \\
\hline Candida tropicalis ATCC 750 & $0.24 \pm 0.03^{a}$ & $0.69 \pm 0.01^{b}$ & $0.51 \pm 0.001^{c}$ & $0.74 \pm 0.03^{b}$ \\
\hline Yarrowia lipolytica W29 & $0.07 \pm 0.02^{\mathrm{a}}$ & $0.06 \pm 0.02^{\mathrm{a}}$ & ND & ND \\
\hline Yarrowia lipolytica CBS 2075 & $1.14 \pm 0.03^{\mathrm{a}}$ & ND & $1.14 \pm 0.04^{\mathrm{a}}$ & ND \\
\hline
\end{tabular}
ND-difference not detected.

Among the phenolic compounds studied, Y. lipolytica W29 only grew in catechol, while Y. lipolytica CBS 2075 only grew in tyrosol, with no statistical differences in comparison with the control (YNB, no carbon source). In contrast, Gonçalves et al. [19] reported that $Y$. lipolytica W29 grew well in OMW with approximately $10 \mathrm{~g} \cdot \mathrm{L}^{-1}$ of total phenols. Moreover, the addition of catechol to a yeast suspension led to an inhibitory effect on the respiratory activity of Y. lipolytica W29, since the oxygen uptake rate (OUR) was considerably lower than the endogenous value. However, the respiratory activity experiments demonstrated that tyrosol had no inhibitory effect on OUR. Theerachat et al. [25] also reported that $Y$. lipolytica $\mathrm{rM}-4 \mathrm{~A}$ had the ability to grow well in palm oil mill effluent with $9.8 \mathrm{~g} \cdot \mathrm{L}^{-1}$ of total phenols. Lopes et al. [11] concluded that Y. lipolytica W29 and Y. lipolytica IMUFRJ 50682 were able to grow in OMW with $0.8 \mathrm{~g} \cdot \mathrm{L}^{-1}$ total phenols concentration.

The results obtained in these first screening trials demonstrated that, among the strains tested, C. tropicalis ATCC 750 was the most efficient at growing in phenolic compounds as sole carbon and energy sources, being a potential microorganism for degrading wastewaters rich in phenolic compounds, such as OMW.

\subsection{Candida tropicalis ATCC 750 Growth in OMW-Based Medium}

OMWs are liquid effluents characterized by the presence of phenolic compounds and their toxicity has mainly been attributed to these compounds $[1,10]$. Candida tropicalis ATCC 750, previously selected due to its ability to grow in some phenolic compounds found in OMW, was used in batch cultures in microscale experiments carried out in 96well microplates (Figure 1), in order to study the effect of the OMW concentration and, consequently, the initial phenolic compounds concentration, on C. tropicalis growth.

Candida tropicalis was able to grow in all tested OMW concentrations and the rise of the initial phenolic compounds concentration (up to $2.4 \mathrm{~g} \cdot \mathrm{L}^{-1}$ ) as a result of the OMW increase up to $50 \%(v / v)$ did not inhibit yeast growth. A 1.6-fold improvement of cellular growth was observed when increasing the OMW concentration from $5 \%$ to $15 \%$, but no further improvement was obtained for more concentrated OMW-based medium. This may indicate that the short incubation time limited the utilization of nutrients in the medium or other environmental factors could be growth-limiting. Nevertheless, it is worth noting that the concentration of phenolic compounds in the least diluted medium is relatively higher compared to others reported in the literature, thus highlighting the high capacity of C. tropicalis ATCC 750 to grow in OMW. 


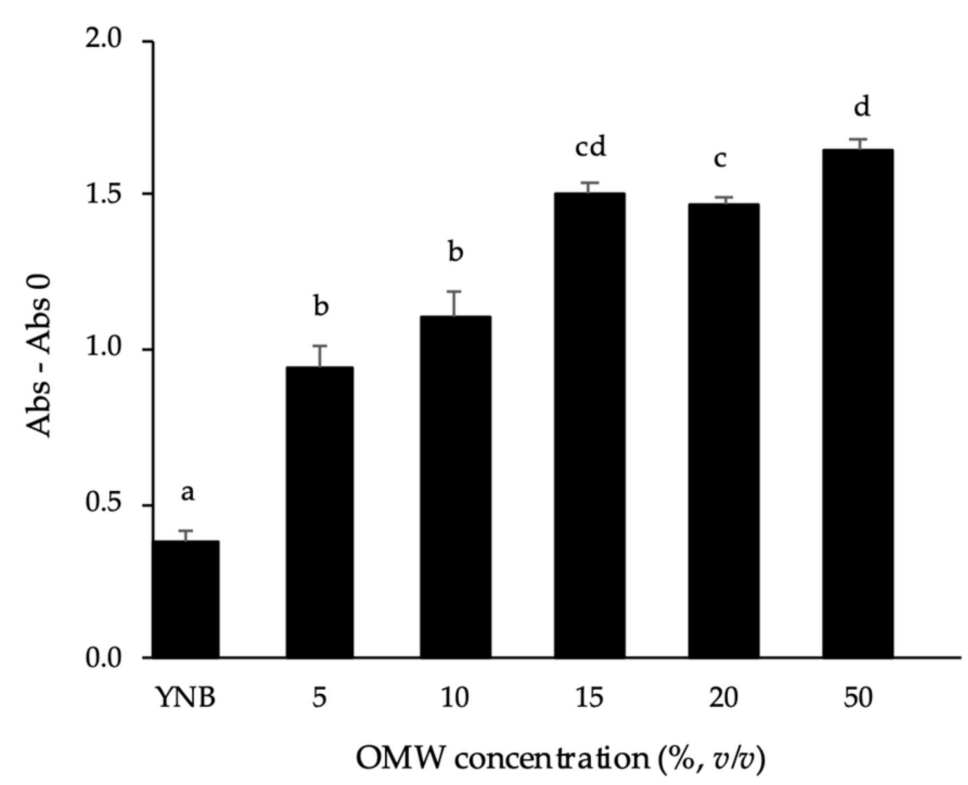

Figure 1. Candida tropicalis ATCC 750 growth in several OMW-1 concentrations evaluated by the difference in the optical density $(\lambda=600 \mathrm{~nm})$ at the end $(48 \mathrm{~h})$ and at the beginning $(0 \mathrm{~h})$ of the experiments. YNB medium was used as the control. The error bars represent the standard deviation of three independent replicates. Bars with the same letter do not present statistically significant differences $(p \leq 0.05)$.

Dourou et al. [12] observed that $C$. tropicalis LFMB 16 grew up to a maximum biomass of $2.6 \mathrm{~g} \cdot \mathrm{L}^{-1}$ in diluted OMW supplemented with glucose $\left(1.2 \mathrm{~g} \cdot \mathrm{L}^{-1}\right.$ initial phenolic compounds) and a remarkable decolorization of OMW was reported. Jarboui et al. [26] showed that the inhibitory effect of phenolic compounds on Rhodotorula mucilaginosa growth decreased with an increase in OMW dilutions. Schwanniomyces etchellsii M2 growth was inhibited by undiluted OMW, while Candida pararugosa BM24 growth was similar in diluted $(50 \%)$ and undiluted OMW experiments [14]. The accumulation of phenolic compounds in the media (up to $4.5 \mathrm{~g} \cdot \mathrm{L}^{-1}$ ), due to the increase of the OMW volume, decreased the maximum values of $Y$. lipolytica strains' biomass $[5,10,27]$.

\subsection{OMW Degradation in Batch Cultures}

In general, OMWs are poor in nitrogen, impairing microbial growth and consequently, the organic compounds consumption of OMW. Although some studies have reported that the addition of an external nitrogen source is not required for yeast growth and OMWcomponents reduction $[15,28]$, others have stated the opposite $[11,13,14,19]$. Therefore, for the strain selected in this work, batch cultures in Erlenmeyer flasks were performed to analyze the OMW degradation performance of the yeast and to study the effect of nitrogen supplementation (Table 4).

The OMW composition may differ according to olive oil processing, olive cultivars, and the campaign year, which may lead to differences in the $\mathrm{C} / \mathrm{N}$ ratio, as was found for OMW-2 and OMW-3 used in this work. In spite of their degradation by C. tropicalis, a better performance in terms of sugars, total phenols, and COD degradation was observed for OMW-3, which has a smaller $\mathrm{C} / \mathrm{N}$ ratio than OMW-2. In fact, COD degradation of OMW-3 was 4.3-fold higher than that observed for OMW-2. For both OMWs, sugars were the components with the highest degradation and phenolic compounds were the least degraded. 
Table 4. Values of the consumption of reducing sugars (RS), total phenols (TPh), and the chemical oxygen demand (COD) obtained in C. tropicalis ATCC 750 batch cultures carried out in Erlenmeyer flasks with and without the addition of an external nitrogen source. Data are the average \pm standard deviation of two independent replicates. Values followed by the same letter in each column do not present statistically significant differences $(p \leq 0.05)$.

\begin{tabular}{|c|c|c|c|c|}
\hline Medium & C/N Ratio & RS (\%) & TPh (\%) & COD (\%) \\
\hline OMW-2 & 132 & $72.8 \pm 1.7^{a}$ & $14.8 \pm 0.1^{\mathrm{a}}$ & $13.9 \pm 2.5^{a}$ \\
\hline OMW-3 & 24 & $87.2 \pm 0.4^{b}$ & $35.0 \pm 0.6^{\mathrm{b}, \mathrm{c}}$ & $59.84 \pm 0.05^{b}$ \\
\hline $\mathrm{OMW}-1+\mathrm{NH}_{4} \mathrm{Cl}$ & 19 & $79.0 \pm 0.4^{\mathrm{a}, \mathrm{b}}$ & $32.7 \pm 0.7^{b, c, d}$ & $48.5 \pm 2.0^{\mathrm{c}}$ \\
\hline $\mathrm{OMW}-2+\mathrm{NH}_{4} \mathrm{Cl}$ & 9 & $79.1 \pm 0.4^{\mathrm{ab}}$ & $27.9 \pm 1.2^{\mathrm{c}, \mathrm{d}}$ & $40.6 \pm 0.2^{c, d}$ \\
\hline $\mathrm{OMW}-3+\mathrm{NH}_{4} \mathrm{Cl}$ & 5 & $86.8 \pm 2.4^{b}$ & $39.6 \pm 0.4^{b}$ & $61.9 \pm 4.0^{\mathrm{b}}$ \\
\hline $\mathrm{OMW}-1+\left(\mathrm{NH}_{4}\right)_{2} \mathrm{SO}_{4}$ & 19 & $74.7 \pm 1.6^{\mathrm{a}}$ & $19.6 \pm 2.7^{\mathrm{a}, \mathrm{e}}$ & $39.5 \pm 2.2^{c, d}$ \\
\hline OMW-2 + Urea & 9 & $74.8 \pm 0.3^{\mathrm{a}}$ & $25.3 \pm 1.2^{\mathrm{d}, \mathrm{e}}$ & $36.3 \pm 0.3^{d}$ \\
\hline
\end{tabular}

The nitrogen supplementation of OMW-2 and OMW-3 with $\mathrm{NH}_{4} \mathrm{Cl}$ improved total phenols and COD reduction, most significantly for OMW-2, for which a 1.9-fold and 2.9-fold degradation increase was observed for total phenols and COD, respectively. These results suggest that nitrogen is important for the consumption of OMW phenolic compounds by C. tropicalis, indicating a relation with the better cellular growth obtained in experiments supplemented with a nitrogen source than for the non-supplemented ones (Figure 2a). In cultures with OMW-2 without nitrogen supplementation, cellular growth was very low and, consequently, lower values of the uptake rate of sugars and total phenols were observed (Figure $2 b, c)$ compared to the other experiments, where the most significant consumption of sugars and total phenols occurred in the first 24 to $48 \mathrm{~h}$. It is worth noting that cellular growth was higher in experiments with OMW-3 than OMW-2, both without nitrogen supplementation, probably due to the lower $\mathrm{C} / \mathrm{N}$ ratio and lower content of total phenols of OMW-3 than OMW-2.

Nitrogen has been reported to be required to improve aromatic compounds biodegradation [24]. The addition of ammonium chloride had a positive effect on COD and total phenols reduction by C. pararugosa BM24, S. etchellsii M2 [14], and C. cylindracea NRRL Y-17506 [18]. The consumption of OMW polyphenols by Candida sp. cultures was favored by the addition of urea [29].

The supplementation of OMW-based medium with an inorganic nitrogen source was also performed with ammonium sulfate and an organic source (urea). From the results obtained in batch cultures using OMW-1, similar degradation was obtained, except for phenolics, for which $\mathrm{NH}_{4} \mathrm{Cl}$ led to better degradation than $\left(\mathrm{NH}_{4}\right)_{2} \mathrm{SO}_{4}$. Lopes et al. [11] showed that OMW-based medium supplementation with ammonium sulfate improved organic matter consumption by Y. lipolytica W29.

The organic nitrogen source studied-urea-did not improve OMW degradation compared to the experiments with $\mathrm{NH}_{4} \mathrm{Cl}$, since similar results were obtained for the organic matter consumption of OMW-2. In addition to nitrogen, it was also reported that the reduction of COD and total phenols in diluted OMW-based media by C. tropicalis strains was favored by the addition of phosphorus and sulfate [13,30].

In general, and independently of OMW supplementation, high values of the $\mathrm{C} / \mathrm{N}$ ratio negatively affected the reductions of sugars, total phenols, and COD. Since, in this study, a higher $\mathrm{C} / \mathrm{N}$ ratio implies a less nitrogen concentration, these results prove the important role of this parameter in the C. tropicalis performance. In general, the values of total phenols reduction obtained in this study (Table 4) were lower than those reported by Martinez-Garcia et al. [13] and Fadil et al. [29] (60\% and 58\%, respectively) for $C$. tropicalis strains, but higher than those obtained by Badr et al. [24], Ettayebi et al. [31], and Dourou et al. [12] $(8 \%, 12 \%$, and $17 \%$, respectively) in experiments with this yeast. Values of COD reduction between $40 \%$ and $71 \%$ were described in OMW biodegradation by $C$. tropicalis $[13,30,31]$. These different results found in the literature for $C$. tropicalis may be 
ascribed to the variability of the OMW composition, mainly the concentration of phenolic compounds.

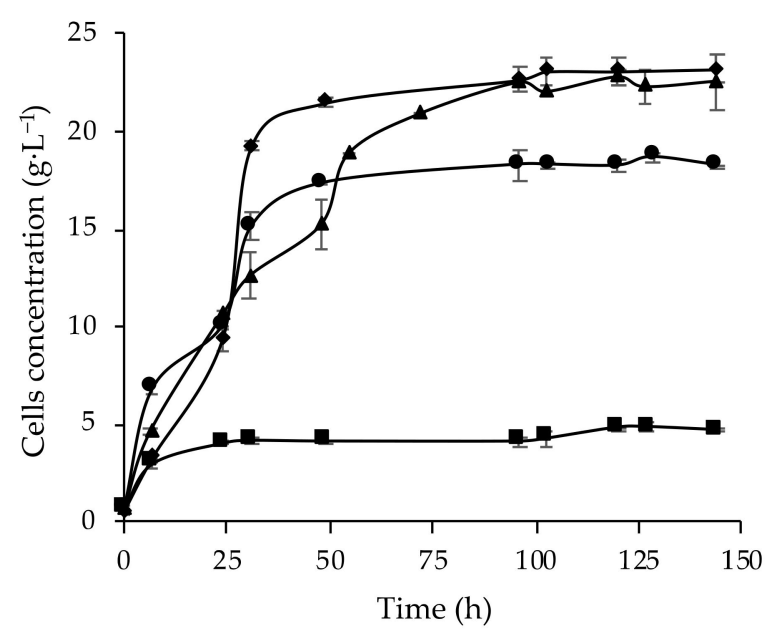

(a)

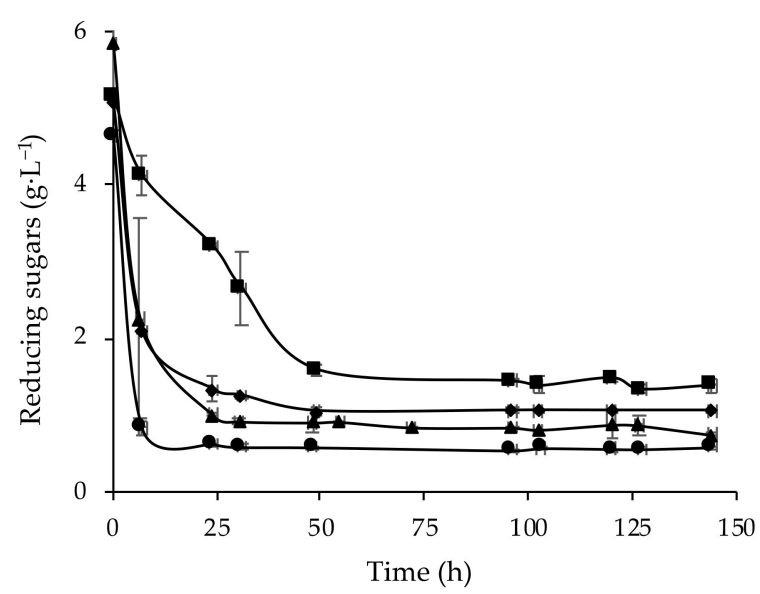

(b)

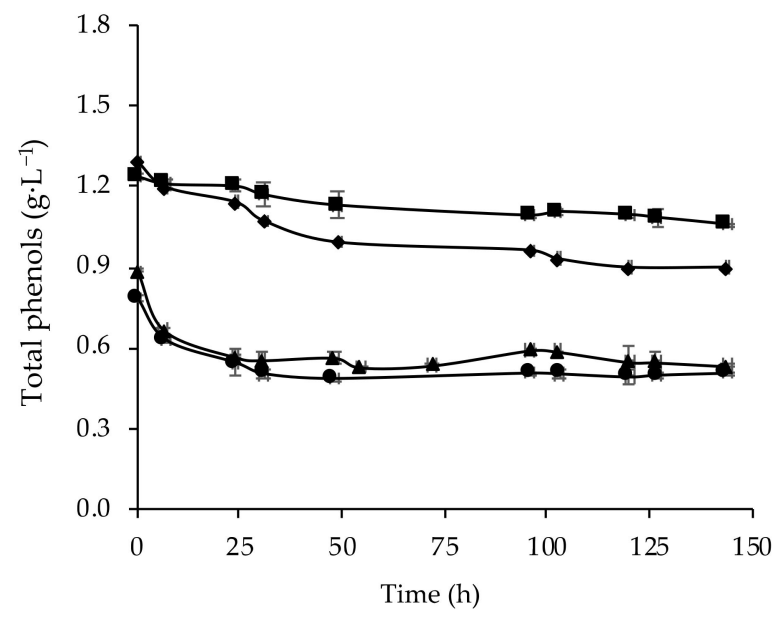

(c)

Figure 2. Time course of cellular growth (a), reducing sugar concentration (b), and total phenol concentration (c) obtained in C. tropicalis ATCC 750 batch cultures carried out in Erlenmeyer flasks: OMW-2 without nitrogen supplementation ( $\mathbf{\square})$; OMW-3 without nitrogen supplementation (•); OMW-2 $+\mathrm{NH}_{4} \mathrm{Cl}(\bullet)$; and OMW-3 $+\mathrm{NH}_{4} \mathrm{Cl}(\boldsymbol{\Delta})$. The error bars represent the standard deviation of two independent replicates.

\subsection{Enzyme and Lipid Production}

Lipidic substrates are usually good inductors of lipase production by some yeast species [32]. As OMW contains variable quantities of olive oil, it can be used as a substrate by yeast for the production of lipolytic enzymes. In fact, C. cylindracea, C. rugosa, and Y. lipolytica have already been described as lipase producers from OMW $[11,18,19]$. However, there are no reports regarding lipase production by $C$. tropicalis in this wastewater. In general, the values of lipase activity obtained in this study (Table 5) were lower than those reported by Gonçalves et al. [19] for C. cylindracea, C. rugosa, and Y. lipolytica strains, but comparable to the enzyme activity obtained by Lopes et al. [11] in experiments with $Y$. lipolytica W29 and IMUFRJ 50682 strains. The differences in lipase production found in the literature for the same yeast strains may be ascribed to the variability of the OMW composition, particularly the sugar content, which can repress lipase induction [33]. Moreover, the considerable amounts of protease secreted by $C$. tropicalis in this study may have led to the degradation of lipase. The supplementation of OMW with inorganic nitrogen sources 
did not improve lipase production, but a significant enhancement in enzyme activity was observed by the addition of organic nitrogen (urea). In fact, organic nitrogen sources were reported as being better inducers of lipase than mineral nitrogen sources [34]. It is also noteworthy that, for OMW-2, the protease activity was lower in experiments supplemented with urea, which also explains the higher lipase production obtained in such conditions.

Table 5. Lipid content (LC), lipid concentration (LConc), and maximum activity of lipase (Lip $\max$ ) and protease (Prot ${ }_{\text {max }}$ ) obtained in C. tropicalis ATCC 750 batch cultures carried out in Erlenmeyer flasks with and without the addition of an external nitrogen source. Data are the average \pm standard deviation of two independent replicates. Values followed by the same letter in each column do not present statistically significant differences $(p \leq 0.05)$.

\begin{tabular}{|c|c|c|c|c|c|}
\hline Medium & C/N Ratio & $\mathrm{LC}(\%, w / w)$ & LConc $\left(g \cdot L^{-1}\right)$ & $\underset{\left(\mathbf{U} \cdot \mathbf{L}^{-1}\right)}{\operatorname{Lip}_{\max }}$ & $\begin{array}{l}\operatorname{Prot}_{\max } \\
\left(\mathrm{U} \cdot \mathbf{L}^{-1}\right)\end{array}$ \\
\hline OMW-2 & 132 & $78.7 \pm 4.7^{\mathrm{a}}$ & $2.7 \pm 0.5^{\mathrm{a}, \mathrm{b}}$ & $25 \pm 3^{a}$ & $2467 \pm 146^{a}$ \\
\hline OMW-3 & 24 & $11.4 \pm 0.6^{\mathrm{b}, \mathrm{c}}$ & $2.1 \pm 0.1^{\mathrm{a}, \mathrm{b}}$ & $29 \pm 3^{a b}$ & $1102 \pm 47^{b}$ \\
\hline $\mathrm{OMW}-1+\mathrm{NH}_{4} \mathrm{Cl}$ & 19 & $32.4 \pm 2.7^{\mathrm{d}}$ & $8.0 \pm 0.1^{c}$ & $49 \pm 4^{c}$ & $1992 \pm 135^{c}$ \\
\hline $\mathrm{OMW}-2+\mathrm{NH}_{4} \mathrm{Cl}$ & 9 & $7.9 \pm 0.8^{c}$ & $1.8 \pm 0.2^{\mathrm{a}, \mathrm{b}}$ & $23 \pm 2^{a}$ & $2340 \pm 198^{a}$ \\
\hline $\mathrm{OMW}-3+\mathrm{NH}_{4} \mathrm{Cl}$ & 5 & $7.5 \pm 1.6^{c}$ & $1.7 \pm 0.5^{b}$ & $49 \pm 4^{c}$ & $742 \pm 42^{b}$ \\
\hline $\mathrm{OMW}-1+\left(\mathrm{NH}_{4}\right)_{2} \mathrm{SO}_{4}$ & 19 & $20.4 \pm 3.6^{b}$ & $3.1 \pm 0.5^{\mathrm{a}, \mathrm{b}, \mathrm{d}}$ & $38 \pm 5^{b}$ & $1175 \pm 35^{b}$ \\
\hline OMW-2 + Urea & 9 & $13.3 \pm 1.4^{b, c}$ & $3.5 \pm 0.2^{a, d}$ & $111 \pm 8^{\mathrm{d}}$ & $1061 \pm 79^{b}$ \\
\hline
\end{tabular}

In addition to lipase and protease production, cells of C. tropicalis were able to accumulate intracellular lipids from OMW in all conditions tested (Table 5). To the best of our knowledge, this is the first work reporting the production of microbial lipids by $C$. tropicalis growing in this wastewater. The content of microbial lipids ranged from $8 \%$ to $79 \%$, depending on the culture conditions, proving that this yeast may be considered an oleaginous yeast and has the potential to accumulate significant amounts of intracellular lipids from OMW.

The $\mathrm{C} / \mathrm{N}$ ratio is a factor with a major influence on lipid accumulation by $\mathrm{C}$. tropicalis, as seen in the results in Table 5, where the highest lipid content of yeast cells occurred in experiments with medium conditions and a high $\mathrm{C} / \mathrm{N}$ ratio. Indeed, the highest value of lipid accumulation was obtained in the experiment without nitrogen supplementation and the highest $\mathrm{C} / \mathrm{N}$ ratio of 132 with OMW-2. However, as in this case cellular growth was weak, the total amount of lipids produced was low and statistically equal to that obtained with OMW-3, which contains more nitrogen. The highest lipid production $\left(8 \mathrm{~g} \cdot \mathrm{L}^{-1}\right)$ was obtained in experiments carried out with OMW-1 and a C/N ratio of 19, as a result of lipid accumulation in the cells and cell growth. Moreover, $\mathrm{NH}_{4} \mathrm{Cl}$ supplementation was more efficient for lipid production from OMW-1 than $\left(\mathrm{NH}_{4}\right)_{2} \mathrm{SO}_{4}$. In contrast, urea was found to be more suitable than $\mathrm{NH}_{4} \mathrm{Cl}$ for lipid production in experiments performed with OMW-2 and a C/N ratio of 9. Cultures of C. tropicalis SY005, growing in basal medium with glucose, increased their intracellular lipid content in conditions of nitrogen limitation and a high $\mathrm{C} / \mathrm{N}$ ratio (150) [35]. Other oleaginous yeasts, such as Y. lipolytica [27,36] and Lipomyces starkeyi [12], have demonstrated the potential to accumulate lipids in nitrogen-limited OMW media with a high $\mathrm{C} / \mathrm{N}$ ratio. Similarly, an increase of the nitrogen concentration in fat-based medium had a negative effect on lipid accumulation by Y. lipolytica strains [37,38]. The possibility to obtain high lipid production without extra nitrogen supplementation and using a low-cost feedstock is an advantage at an industrial level, since the costs of raw materials account for a large percentage of global costs of this process. Therefore, the production of microbial lipids by $C$. tropicalis from non-supplemented OMW has the potential to be a competitive process. It is worth noting that the lipid content in these conditions $(78.7 \%, w / w)$ is one of the highest reported in the literature for non-genetically modified oleaginous yeasts.

In general, lipid accumulation by oleaginous yeasts involves two distinct metabolic pathways: de novo synthesis from hydrophilic substrates (e.g., sugars and glycerol) and 
ex novo synthesis from hydrophobic substrates (e.g., oils, fats, and hydrocarbons). In the first approach, lipid synthesis occurs during the stationary growth phase under excess carbon and limited nutrient conditions (usually nitrogen) and is dependent on the C/N ratio. In contrast, ex novo synthesis occurs simultaneously with cell growth, being entirely independent of nutrient exhaustion and the $C / N$ ratio $[36,39,40]$. Since OMW contains both hydrophilic (sugars) and hydrophobic (olive oil) substrates in its composition, the lipids synthetized by $C$. tropicalis in these conditions may have occurred simultaneously by de novo and ex novo pathways. Though the highest lipid content was obtained in the nonsupplemented experiments (OMW-2), the maximum lipid concentration was attained with $\mathrm{OMW}-1+\mathrm{NH}_{4} \mathrm{Cl}$ due to the greater amount of final biomass in these conditions. Therefore, a two-stage bioprocess could be attempted to increase microbial lipid production by $C$. tropicalis from OMW: A growth phase in $\mathrm{OMW}$ with $\mathrm{NH}_{4} \mathrm{Cl}$ supplementation to obtain high-cell density cultures, followed by nitrogen-limited conditions for lipid synthesis.

Lipid production by C. tropicalis was not affected by the phenols concentration, since the maximum lipid contents were obtained in experiments in which OMW had a higher amount of phenols. Sarris et al. [5] reported that no correlation can be established between lipid accumulation by the two Y. lipolytica strains studied and an increase of the initial phenolic compounds concentration in OMW.

Fatty acid analysis of intracellular lipids showed that oleic acid is by far the fatty acid most accumulated (69\% to $76 \%$ of total fatty acids) by C. tropicalis cells (data not shown). Other fatty acids present are linoleic ( $5 \%$ to $16 \%$ ), palmitic ( $9 \%$ to $17 \%)$, and stearic (1\% to $5 \%$ ) acid. This composition is not at all surprising, since OMW contains olive oil, which is mainly composed of oleic acid, and in the ex novo lipid synthesis, the profile of accumulated lipids can be similar to the composition of an oily substrate [41]. Cells of Y. lipolytica and $L$. starkeyi, growing in OMW-based medium, also synthetized lipids rich in oleic acid [12].

In general, the supplementation of OMW with extra nitrogen, as well the total phenols concentration in OMW, did not affect the fatty acids profile. Nevertheless, the supplementation of OMW-3 with $\mathrm{NH}_{4} \mathrm{Cl}$ led to an increase of stearic and oleic acids and decrease of linoleic acid in comparison to the OMW-3 non-supplemented experiment. In Y. lipolytica cultures, the addition of OMW to glucose-based medium favored the synthesis of higher unsaturated lipids due to an enhancement of acyl- $\Delta^{9}$-desaturase activity as a physiological response of yeast cells to a high phenols concentration $[5,10]$.

A principal component analysis (PCA) was performed for experiments with $\mathrm{NH}_{4} \mathrm{Cl}$ supplementation, in order to assess the relationship between the OMW composition, reduction of OMW components (sugars, phenols, and COD), enzyme (lipase and protease) production, and lipids accumulated intracellularly. This is the first time that such analysis has been performed for $C$. tropicalis culture in OMW. PCA allowed a small number of linear combinations of the 13 variables studied to be obtained, in order to explain the variability of the data. In this analysis, two components-PC1 (64.33\%) and PC2 (35.67\%)—were shown to explain $100 \%$ of the variability of the original data (Figure 3).

PC1 was positively characterized by the $\mathrm{C} / \mathrm{N}$ ratio, microbial lipid content, total phenols, reducing sugars, COD, and TOC, and negatively characterized by the biomass concentration and reducing sugars consumption. The negative effect of the total phenols content and C/N ratio on the biomass concentration is clearly visible. Sarris et al. [10] also observed that the maximum values of $Y$. lipolytica biomass decreased with the phenolic content increase in OMW-medium. The $\mathrm{C} / \mathrm{N}$ ratio and the amount of reducing sugars, total phenols, COD, and TOC present in OMW positively influenced the microbial lipid content. As previously mentioned, an excess of the carbon source in the medium and, consequently, a higher $\mathrm{C} / \mathrm{N}$ ratio, were reported to be essential for de novo lipid synthesis $[39,40]$. The negative effect of growth in the lipid content was also noticeable. In fact, carbon sources present in the medium were either being assimilated by the yeast for its growth or were being used for the production of the lipids, so the deviation of metabolism to one of these pathways minimizes the other. 


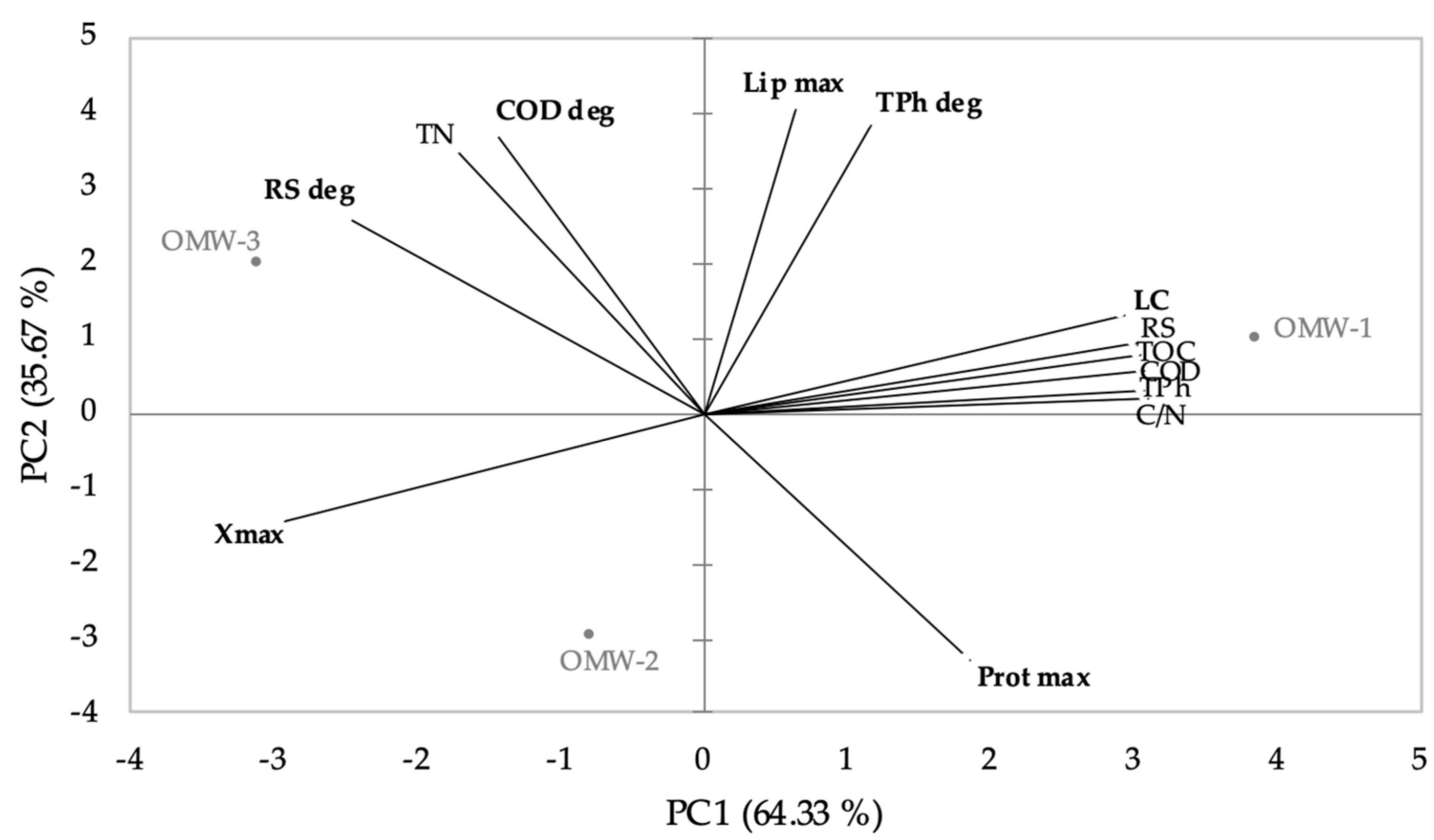

Figure 3. Principal component analysis (PCA) relating the OMW composition- $\mathrm{C} / \mathrm{N}$ ratio $(\mathrm{C} / \mathrm{N}), \mathrm{COD}$, total organic carbon (TOC), total nitrogen (TN), total phenols (TPh), and reducing sugars (RS); reduction of OMW components-sugars (RS deg), total phenols (TPh deg), and COD (COD deg); biomass concentration (Xmax); enzyme production-lipase (Lip max) and protease (Prot max); and microbial lipid content (LC). Biplot representation of variables and scores of the OMW, defined by the first principal component (PC1) and second principal component (PC2).

For PC2, cell growth and protease activity were negatively characterized and all the other parameters correlated positively. The positive effect of the nitrogen amount on COD and sugars reduction is clearly visible. This observation supports the fact that nitrogen supplementation is crucial for OMW-component reduction. The production of extracellular lipases can be affected by prolonged fermentation times due to the release of extracellular proteases that degrade lipases $[17,32,42]$. This indirect relation between lipase and protease production is evident in this PCA.

The three OMWs used in this work are separated in Figure 3, demonstrating that this PCA did not group any OMW, and showing that each OMW has different influences on the studied parameters. In fact, OMW-1 was clearly characterized as a wastewater with a high content of reducing sugars, TOC, COD, and total phenols and low content of total nitrogen. On the contrary, OMW-3 was highly correlated with a high content of total nitrogen and low content of reducing sugars, TOC, COD, and total phenols.

\subsection{Bioreactor Experiments}

Besides the definition of the medium composition, environmental and operational conditions are determinant for the successful scale-up of bioprocesses. Therefore, the effect of $\mathrm{pH}$-controlled (5.5 and 7) and oxygenation conditions, and a varying agitation rate (200 and $500 \mathrm{rpm}$ ), on OMW-3 biodegradation and metabolites production by C. tropicalis was studied for the first time in a lab-scale bioreactor.

The increase of the medium $\mathrm{pH}$ from 5.5. to 7 led to an enhancement of $C$. tropicalis growth and a 1.3- and 1.2-fold improvement in the final biomass and specific growth rate, respectively, were obtained in experiments carried out at pH 7 (Figure 4a) compared to those at $\mathrm{pH}$ 5.5. In both conditions, a stationary growth phase was reached after approximately $50 \mathrm{~h}$ of cultivation. As observed in Erlenmeyer flask experiments, also at a bioreactor scale, the consumption of sugars and phenolic compounds occurred in the first 24 and $48 \mathrm{~h}$, respectively, remaining almost constant at the end of the experiments (Figure $4 \mathrm{~b}$ ). No differences were observed in the sugars and total phenols consumption profiles at $\mathrm{pH} 5.5$ 
and 7. In fact, the total reduction of sugars, phenols, and COD was statistically equal at both $\mathrm{pH}$ values (Table 6). Although several studies with $C$. tropicalis strains on OMW have been carried out at a slightly acidic pH (5-6) [12,24,30], Koubeissi et al. [43] concluded that 7 was the best $\mathrm{pH}$ for $\mathrm{C}$. tropicalis growth and phenols consumption in a synthetic medium.

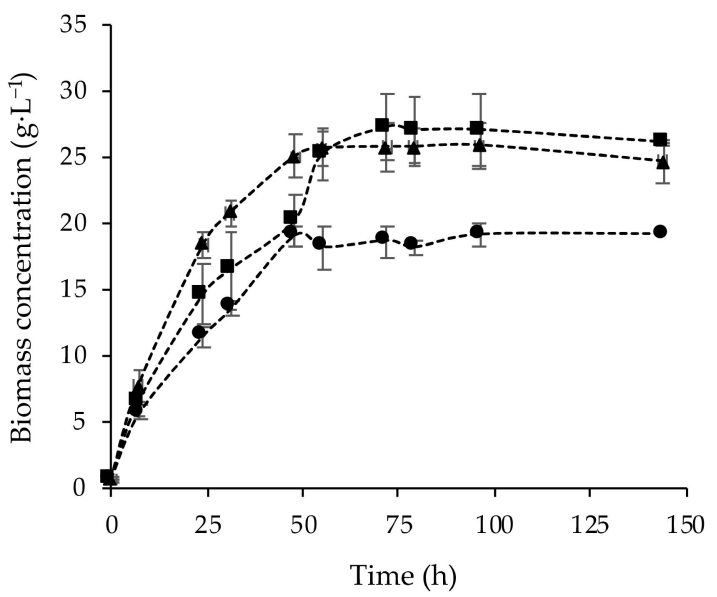

(a)

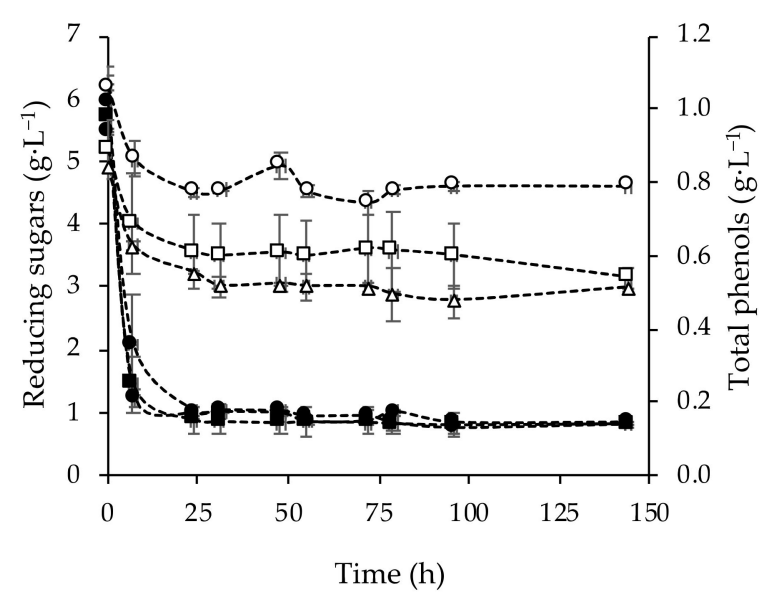

(b)

Figure 4. Time course of cellular growth (a), reducing sugars (closed symbols), and the total phenols (open symbols) concentration (b) obtained in C. tropicalis batch cultures carried out in a lab-scale bioreactor at pH 5.5 and $200 \mathrm{rpm}(\bullet$, $\bigcirc)$, pH 7 and $200 \mathrm{rpm}$ independent replicates.

$\square)$, and $\mathrm{pH} 7$ and $500 \mathrm{rpm}(\boldsymbol{\Lambda}, \Delta)$. The error bars represent the standard deviation of two

Table 6. Values of consumption of the reducing sugars (RS), total phenols (TPh), chemical oxygen demand (COD), total organic carbon (TOC), total nitrogen (TN), and maximum activity of lipase $\left(\right.$ Lip $\left._{\max }\right)$ and protease (Prot ${ }_{\max }$ ) obtained in C. tropicalis ATCC 750 batch cultures carried out in a lab-scale bioreactor at pH 5.5 and $200 \mathrm{rpm}, \mathrm{pH} 7$ and $200 \mathrm{rpm}$, and pH 7 and $500 \mathrm{rpm}$. Data are the average \pm standard deviation of two independent replicates. Values followed by the same letter in each row do not present statistically significant differences $(p \leq 0.05)$.

\begin{tabular}{cccc}
\hline & pH 5.5 200 rpm & pH 7.0 200 rpm & pH 7.0 500 rpm \\
\hline RS (\%) & $84.6 \pm 0.6^{\mathrm{a}}$ & $84.4 \pm 2.5^{\mathrm{a}}$ & $86.4 \pm 0.7^{\mathrm{a}}$ \\
TPh (\%) & $25.4 \pm 1.7^{\mathrm{a}}$ & $33.3 \pm 4.7^{\mathrm{ab}}$ & $39.1 \pm 0.2^{\mathrm{b}}$ \\
COD (\%) & $64.6 \pm 4.5^{\mathrm{a}}$ & $61.3 \pm 4.3^{\mathrm{a}}$ & $68.2 \pm 6.0^{\mathrm{a}}$ \\
TOC (\%) & - & $56.8 \pm 4.0^{\mathrm{a}}$ & $58.7 \pm 4.1^{\mathrm{a}}$ \\
TN (\%) & - & $52.7 \pm 3.7^{\mathrm{a}}$ & $47.5 \pm 3.3^{\mathrm{a}}$ \\
Lipmax $_{\operatorname{ma}}\left(\mathrm{U} \cdot \mathrm{L}^{-1}\right)$ & $203 \pm 18^{\mathrm{a}}$ & $118 \pm 12^{\mathrm{b}}$ & $51 \pm 6^{\mathrm{c}}$ \\
Prot $_{\text {max }}\left(\mathrm{U} \cdot \mathrm{L}^{-1}\right)$ & $713 \pm 95^{\mathrm{a}}$ & $752 \pm 5^{\mathrm{a}}$ & $1105 \pm 9^{\mathrm{b}}$ \\
\hline
\end{tabular}

In the experimental conditions tested herein, lipase production by $C$. tropicalis reached its maximum value at $\mathrm{pH} 5.5$ and a 1.7-fold improvement of enzyme activity was attained compared to the experiments at $\mathrm{pH} 7$. It should be noted that a four-fold improvement in lipase activity was obtained in the bioreactor at $\mathrm{pH} 5.5$ compared to the experiments performed in Erlenmeyer flasks in the same conditions (OMW-3 $+\mathrm{NH}_{4} \mathrm{Cl}, \mathrm{C} / \mathrm{N}$ ratio of 5, and initial $\mathrm{pH}$ of 5). This result may be attributed to the fact that, in the bioreactor, the $\mathrm{pH}$ was controlled during all experiments. In contrast, Peng et al. [44] found that 7 was the best $\mathrm{pH}$ value for lipase secretion by $\mathrm{C}$. tropicalis SD7 in olive oil. The maximum lipase activity obtained in Y. lipolytica W29 cultures, growing in pork lard and waste cooking oils, was obtained at $\mathrm{pH} 5.6$ and 7.2 , respectively $[17,36]$. Protease production was not affected by the medium $\mathrm{pH}$ and a similar enzyme activity was obtained in both conditions.

The amount of oxygen available in OMW medium is an important parameter to take into account for efficient yeast growth and OMW biodegradation. Furthermore, as OMWs contain olive oil, adequate mixing conditions are required for a good dispersion 
of oil in the liquid medium, which are promoted by efficient agitation. Therefore, two agitation rates were tested, and no differences regarding C. tropicalis ATCC 750 growth were obtained when increasing the agitation from 200 to $500 \mathrm{rpm}$ (Figure 4a). The same behavior was observed for OMW-components consumption, and the total reduction of sugars, total phenols, COD, TOC, and TN displayed no statistical differences at 200 and $500 \mathrm{rpm}$ (Table 6). In the first hour of fermentation at $200 \mathrm{rpm}$, oxygen dropped to zero and remained at this value until $31 \mathrm{~h}$, corresponding to the exponential growth phase (data not shown). This growth phase was correlated with the consumption of sugars and phenols in the medium (Figure $4 \mathrm{~b}$ ). Thereafter, the dissolved oxygen increased and remained close to $80-90 \%$ during the stationary phase. On the other hand, in the experiment conducted at $500 \mathrm{rpm}$, the oxygen concentration initially decreased until $56 \%$, stabilizing at above $80 \%$ after $10 \mathrm{~h}$ of cultivation (data not shown). The mechanical stress promoted by the impellers and/or oxidative stress caused by the increase of the dissolved oxygen concentration, which resulted from the higher stirring speeds, may explain the results obtained. Other authors have stated that higher agitation rates are preferable for $C$. utilis and S. cerevisiae growth [15] and phenolic compound consumption by Rhodotorula glutinis in OMW-based media [45].

The increase of the agitation rate had a negative influence on lipase secretion. In this way, it is possible to conclude that under these conditions, higher rates of agitation are not needed to increase the enzyme production. This advantage can make this bioprocess economically interesting due to the important reductions in costs with power consumption. In addition to the effect of agitation on lipase production, the release of proteases to the medium must also be taken into account. In opposition to lipolytic activity, protease secretion increased with the raise of the agitation rate. The action of these proteolytic enzymes may have led to the degradation of lipase. The presence of oxygen is essential for lipase production by several microorganisms. In most cases, oxygen seems to favor lipase production; however, low levels of aeration have also been reported to increase the enzyme production. Highly aerated cultures reduced enzyme secretion by Y. lipolytica IMUFRJ 50682 in olive oil due to mechanical and/or oxidative stress [46]. Lopes et al. [42] reported that an oxygen solubility improvement obtained by increasing the total air pressure enhanced lipase production by Y. lipolytica W29 in olive oil, but decreased protease activity.

As occurred in flask-scale experiments, the synthesis of microbial lipids by C. tropicalis cells was also observed in bioreactor cultures. The increase of $\mathrm{pH}$ had a clear positive effect on microbial lipid synthesis and a 2.4-fold improvement in the lipid content was attained at pH 7 (Figure 5). The maximum lipid concentration was also attained with pH 7 due to the greater amount of final biomass in these conditions (Table 7). The value of $\mathrm{pH}$ affects the surface properties of the cell membrane and thereby plays an imperative role in the assimilation of the carbon source, which has consequences in lipid production [47]. The low $\mathrm{pH}$ resulted in low growth due to poor nutrient assimilation by the cells, which altered the cell membrane permeability and consequently decreased lipid accumulation. Contrary to the results obtained in this study, Dey and Maiti [35] found that the de novo lipid accumulation in C. tropicalis SY005 is not apparently affected by altering the $\mathrm{pH}$ between 4 and 7, using glucose as the culture medium. A similar kind of result was also observed in lipid production by another strain of $C$. tropicalis in molasses media [48]. The effect of $\mathrm{pH}$ on lipid production by other oleaginous yeast strains, such as Y. lipolytica, was also evaluated in fat-based medium. A pH of 6.0 was considered to be the most optimum for the lipid concentration and lipid content of Y. lipolytica MTCC 9520 in chicken tallow media [37] and vegetable oil refinery wastewater [49]. Lopes et al. [36] reported that varying the $\mathrm{pH}$ from 7.2 to 5.6 led to an increase of the microbial lipid content by Y. lipolytica W29 in pork lard. 


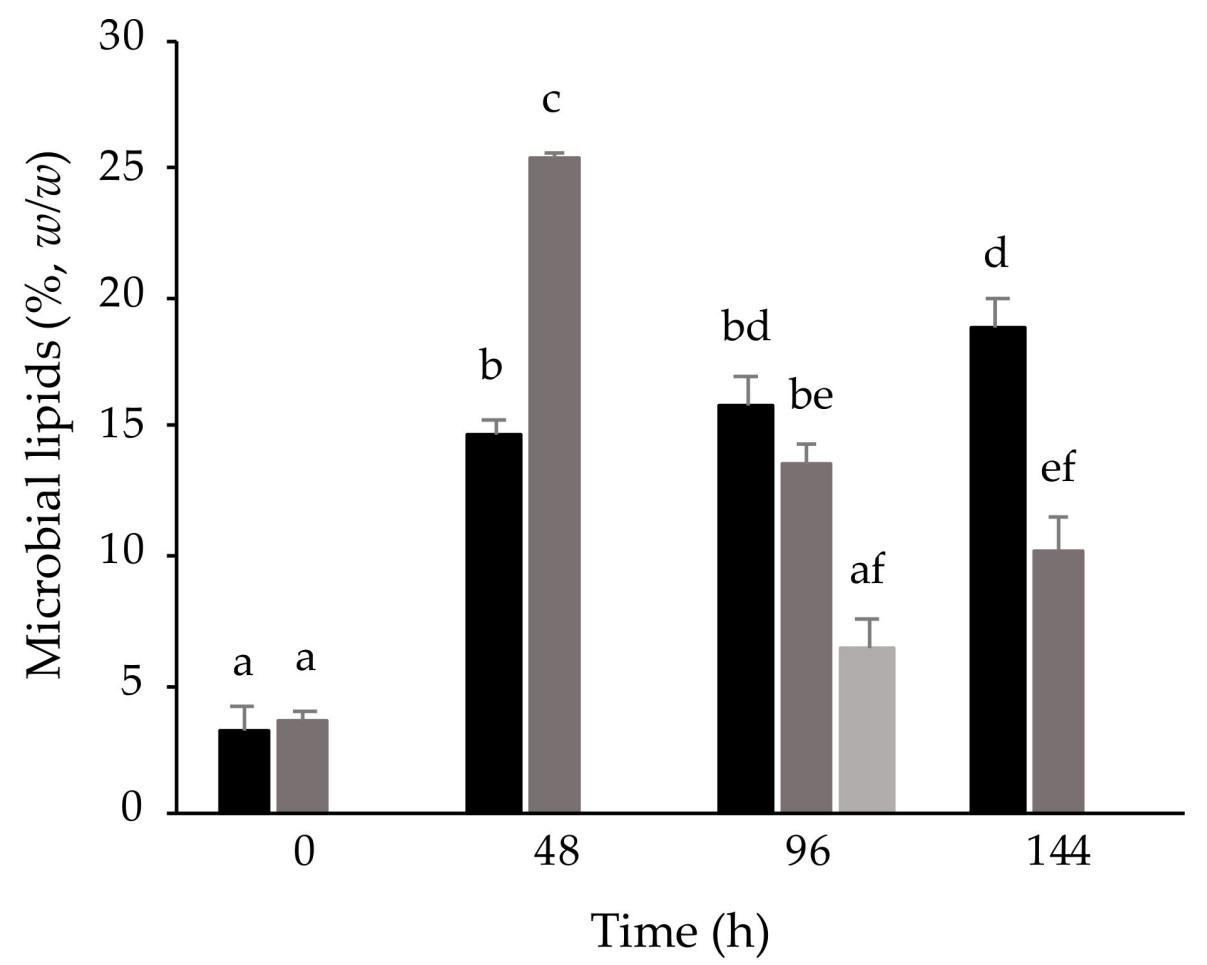

Figure 5. Microbial lipid content of $C$. tropicalis cells obtained in lab-scale bioreactor experiments carried out at pH 7 and 200 rpm (black bars), pH 7 and 500 rpm (dark gray bars), and pH 5.5 and $200 \mathrm{rpm}$ (light gray bars). The error bars represent the standard deviation of two independent replicates. Bars with the same letter do not present statistically significant differences $(p \leq 0.05)$.

Table 7. Lipid concentration (LConc) and long chain fatty acids composition of $C$. tropicalis ATCC 750 cells obtained in a lab-scale bioreactor at pH 5.5 and $200 \mathrm{rpm}, \mathrm{pH} 7$ and $200 \mathrm{rpm}$, and pH 7 and $500 \mathrm{rpm}$. Data are the average \pm standard deviation of two independent replicates. Values followed by the same letter in each column do not present statistically significant differences $(p \leq 0.05)$.

\begin{tabular}{|c|c|c|c|c|c|c|}
\hline & \multirow[b]{2}{*}{ Time } & \multirow[b]{2}{*}{$\begin{array}{c}\text { Lconc } \\
\left(\mathrm{g} \cdot \mathrm{L}^{-1}\right)\end{array}$} & \multicolumn{4}{|c|}{ Long Chain Fatty Acids (\%) } \\
\hline & & & C16:0 & C18:0 & C18:1 & C18:2 \\
\hline $\begin{array}{c}\mathrm{pH} 5.5 \\
200 \mathrm{rpm}\end{array}$ & 96 & $1.4 \pm 0.2^{\mathrm{a}}$ & $13.5 \pm 0.2^{\mathrm{a}, \mathrm{b}}$ & $2.4 \pm 0.3^{a}$ & $71.3 \pm 0.1^{\mathrm{a}}$ & $12.9 \pm 0.4^{\mathrm{a}, \mathrm{b}}$ \\
\hline \multirow{4}{*}{$\underset{\text { rpm }}{\mathrm{pH} 7200}$} & 0 & $0.8 \pm 0.2^{\mathrm{a}}$ & - & - & - & - \\
\hline & 48 & $3.6 \pm 0.2^{b}$ & $9.3 \pm 0.3^{b}$ & $2.7 \pm 0.7^{\mathrm{a}}$ & $76.3 \pm 0.6^{\mathrm{a}}$ & $11.7 \pm 0.2^{b}$ \\
\hline & 96 & $3.8 \pm 0.3^{b, c}$ & $10.7 \pm 0.2^{b}$ & $3.4 \pm 0.6^{\mathrm{a}}$ & $74.0 \pm 0.8^{\mathrm{a}}$ & $12.0 \pm 0.1^{b}$ \\
\hline & 144 & $4.6 \pm 0.3^{c}$ & $10.6 \pm 0.2^{b}$ & $1.5 \pm 0.6^{\mathrm{a}}$ & $73.6 \pm 0.6^{\mathrm{a}}$ & $14.2 \pm 0.2^{\mathrm{a}}$ \\
\hline \multirow{4}{*}{$\underset{\substack{\mathrm{pH} \\
\mathrm{rpm}}}{ }$} & 0 & $0.9 \pm 0.1^{\mathrm{a}}$ & - & - & - & - \\
\hline & 48 & $6.2 \pm 0.02^{d}$ & $16.2 \pm 0.4^{\mathrm{a}}$ & $2.8 \pm 1.4^{\mathrm{a}}$ & $62.2 \pm 1.1^{\mathrm{b}}$ & $18.9 \pm 0.3^{c}$ \\
\hline & 96 & $3.3 \pm 0.2$ be & - & - & - & - \\
\hline & 144 & $2.5 \pm 0.3^{\mathrm{e}}$ & $17.7 \pm 3.4^{\mathrm{a}}$ & $2.9 \pm 1.7^{\mathrm{a}}$ & $59.7 \pm 6.1^{b}$ & $19.7 \pm 1.2^{\mathrm{c}}$ \\
\hline
\end{tabular}

Two different profiles of lipid content were observed: (a) At $500 \mathrm{rpm}$, the lipid content reached a maximum value after $48 \mathrm{~h}$ of cultivation, decreasing after that, and (b) at $200 \mathrm{rpm}$, the lipid content increased throughout the experiment and the maximum value was obtained after $144 \mathrm{~h}$ (Figure 5). The same behavior was observed for the lipid concentration, since no differences in C. tropicalis ATCC 750 growth were obtained when increasing the agitation from 200 to $500 \mathrm{rpm}$. The lipids already accumulated can have an inhibitory effect on the uptake of extracellular fatty acids by cells, leading to the degradation of reserve lipids. Additionally, in the ex novo pathway, as the accumulation of lipids occurs simultaneously with cellular growth, the fast consumption of carbon sources may cause the degradation of storage lipids by yeasts. Sarris et al. $[5,10]$ also showed that the lipid 
concentration of $Y$. lipolytica strains was reduced in the late growth phases. In this study, a higher amount of microbial oils was reached at $500 \mathrm{rpm}$. This result can be attributed to enhancement of the oxygen transfer rate due to more dispersed and smaller gas bubbles at higher agitation rates than at lower ones, and also to the decrease in the liquid resistance to oxygen mass transfer [50]. The increase in the oxygen transfer rate from air to the culture allowed the dissolved oxygen concentration to be maintained at non-limiting concentration values. Bellou et al. [51] reported that an upregulation of lipid metabolism caused by the higher activity of enzymes that participate in lipid synthesis (ATP-citrate lyase and malic enzyme) was achieved by increasing the dissolved oxygen concentration. In these conditions, the maximum lipid content was similar to in other studies found in the literature for Y. lipolytica and L. starkeyi strains cultivated in OMW-based medium [12,27]. Several authors have recognized the importance of oxygen in lipid biosynthesis; however, an increase of aeration is not a guarantee of an increase in lipid accumulation [52,53]. For Y. lipolytica, an oxygen limitation could lead to inhibition in carbon metabolism, resulting in citric acid secretion instead of lipid accumulation [54]. A clear enhancement in lipid accumulation by Y. lipolytica W29 was obtained due to the increase of the oxygen transfer rate or volumetric oxygen transfer coefficient in pork lard [36] and waste cooking oils [17], respectively. On the contrary, an increase in aeration and agitation values led to a significant decrease of lipids accumulated by Y. lipolytica in stearin medium [37] and by L. starkeyi in glucose medium [55].

The fatty acids profile of microbial lipids accumulated was similar for both $\mathrm{pH}$ conditions in bioreactor experiments and oleic acid was the predominant fatty acid, followed by palmitic and linoleic acids (Table 7). It seems that there is no relation between $\mathrm{pH}$ conditions and the fatty acids composition. A low $\mathrm{pH}$ was reported as beneficial for oleic acid synthesis by oleaginous yeast Trichosporon fermentans in a rich-sugar medium [56]. In waste cooking oil-based medium, the content of oleic acid in lipids accumulated by $Y$. lipolytica W29 increased at pH 5.6, while a decrease in linoleic acid was observed [17]. An increase in the oleic and linoleic acid content and a decrease in palmitic and stearic acids were achieved by the same yeast strain when varying the $\mathrm{pH}$ of pork lard-based medium from 5.6 to 7.2 [36].

The agitation had an influence not only on the content of lipids, but also on the profile of the lipid composition (Table 7). The composition of fatty acids did not change over the culture period and oleic acid was the fatty acid predominantly accumulated by $C$. tropicalis ATCC 750 cells in the bioreactor (as was verified in the Erlenmeyer flask experiments). An increase in agitation from 200 to $500 \mathrm{rpm}$ increased the content of palmitic and linoleic acids accumulated, while the oleic acid content decreased. Lopes et al. [36] reported that the unsaturated-to-saturated fatty acids ratio was higher in highly aerated conditions using Y. lipolytica W29 in pork lard. Papanikolaou et al. [37] showed that higher quantities of oleic acid were obtained in highly aerated bioreactor experiments by Y. lipolytica in stearin medium. Conversely, Lopes et al. [17] concluded that there is no relation between the oxygenation conditions and fatty acid composition accumulated by Y. lipolytica W29 in waste cooking oils. This conclusion was also stated by Calvey et al. [55], since the fatty acid composition of lipids accumulated by L. starkeyi was similar for different agitation rates.

Microbial lipids synthetized by $C$. tropicalis from OMW, rich in oleic and linoleic acids, can be used as feedstock for bio-based industry, such as in biodiesel production, in biochemical industry, or as food and feed supplements. Moreover, the lipases and proteases produced are also of great industrial interest. Lipases can also be applied as biocatalysts in biodiesel production, which is generally obtained from edible and nonedible vegetable oils or waste cooking oils. However, vegetable oils are commonly used for human consumption, feed, cosmetics, and oleochemical industries, which will lead to competition for crops and rising oil prices. Additionally, the increased demand for plantderived oils requires the increase of crop fertilization, negatively contributing to greenhouse gas emissions [57]. The high content of water and free fatty acids in waste cooking oils, as well as the presence of glycerides and dimeric and polymeric acids, may interfere in 
the transesterification reactions and affect the final quality of biodiesel. Moreover, the quantity of waste cooking oils available for biodiesel industry is not enough to fulfill the increasing demand of this biofuel [58]. Microalgae biodiesel is approaching commercial viability, but the requirement for sunlight is an inherent limitation [57]. Microbial lipids are new and underexplored alternatives to vegetable oils and animal fats for biodiesel production [59], but their industrial production is still hindered by the high cost of pure substrates, amount of oil accumulated by cells, and oil extraction yield. As yeasts are capable of assimilating a wide variety of substrates, one possible way to reduce the costs of producing microbial lipids, and simultaneously, environmental pollution, is the use of industrial wastes as culture medium. The fermentation of low-cost raw material (OMW) by C. tropicalis ATCC 750 can be used as an indirect way of obtaining biodiesel from lipids produced by this yeast.

\section{Conclusions}

The results reported herein demonstrate the potential application of the non-pathogenic strain of C. tropicalis (ATCC 750) for OMW valorization by its use as a culture medium for biomass, enzyme production, and intracellular lipid synthesis. The utilization of OMW as feedstock for microbial metabolites production can decrease the production costs of the target products and have a positive impact on the environmental issue of OMW management, since it can also act as the first step in effluent treatment. In fact, the partial removal of COD and total phenols present in OMW was performed by this yeast. Taking these facts into account, the bioprocess described herein could be inserted into the concept of a circular economy: OMWs are converted to lipid-rich biomass (that could be used for food supplement, animal feedstock, or biodiesel production) and the production of lipase (that could be used for biodiesel production), resulting in an effluent with a reduced organic load and phenolic compounds concentration. A two-stage bioprocess could be attempted to increase microbial lipids production by C. tropicalis from OMW: A growth phase in OMW with nitrogen supplementation to obtain high-cell density cultures, followed by nitrogenlimited conditions for lipid synthesis. Moreover, environmental operating conditions can be selected according to the desired target bioproduct (lipids, lipases, or proteases) with OMW and C. tropicalis ATCC 750 in the center of a biorefinery approach.

Author Contributions: Conceptualization, M.L. and I.B.; methodology, B.D., R.R., and A.S.P.; software, B.D.; validation, M.L. and I.B.; formal analysis, B.D., M.L., R.R., and I.B.; investigation, B.D., M.L., R.R., and I.B.; data curation, B.D., M.L., R.R., A.S.P., and I.B.; writing—original draft preparation, B.D. and M.L.; writing-review and editing, M.L. and I.B.; visualization, M.L. and I.B.; supervision, M.L. and I.B. All authors have read and agreed to the published version of the manuscript.

Funding: This research was supported by the Portuguese Foundation for Science and Technology (FCT) under the scope of the project TUBITAK 2014 (TUBITAK/0009/2014), the strategic funding of the UIDB/04469/2020 unit, a doctoral grant (SFRH/BD/129592/2017), and the BioTecNorte operation (NORTE-01-0145-FEDER-000004) funded by the European Regional Development Fund under the scope of Norte2020-Programa Operacional Regional do Norte.

Institutional Review Board Statement: Not applicable.

Informed Consent Statement: Not applicable.

Conflicts of Interest: The authors declare no conflict of interest.

\section{References}

1. Rharrabti, Y.; Yamani, M. Olive mill wastewater: Treatment and valorization technologies. In Handbook of Environmental Materials Management; Springer: Berlin, Germany, 2018; pp. 1-28.

2. International Olive Council. Changes in Olive Oil and Table Olive Production; Newsletter International Olive Council: Madrid, Spain, 2019.

3. Caporaso, N.; Formisano, D.; Genovese, A. Use of phenolic compounds from olive mill wastewater as valuable ingredients for functional foods. Crit. Rev. Food Sci. Nutr. 2018, 58, 2829-2841. [CrossRef] [PubMed] 
4. Souilem, S.; El-Abbassi, A.; Kiai, H.; Hafidi, A.; Sayadi, S.; Galanakis, C.M. Olive oil production sector: Environmental effects and sustainability challenges. In Olive Mill Waste: Recent Advances for Sustainable Management; Elsevier Inc.: Amsterdam, The Netherlands, 2017; pp. 1-28.

5. Sarris, D.; Galiotou-Panayotou, M.; Koutinas, A.A.; Komaitis, M.; Papanikolaou, S. Citric acid, biomass and cellular lipid production by Yarrowia lipolytica strains cultivated on olive mill wastewater-based media. J. Chem. Technol. Biotechnol. 2011, 86, 1439-1448. [CrossRef]

6. Tsagaraki, E.; Lazarides, H.N.; Petrotos, K.B. Olive mill wastewater treatment. In Utilization of By-Products and Treatment of Waste in the Food Industry; Springer: Boston, MA, USA, 2006; pp. 133-157.

7. Mostafa, S.S.; El-Hassanin, A.S.; Soliman, A.S.; Rashad, S.; El-Chaghaby, G.A. Microalgae growth in effluents from olive oil industry for biomass production and decreasing phenolics content of wastewater. Egypt. J. Aquat. Biol. Fish. 2019, 23, 359-365. [CrossRef]

8. Baldiris-Navarro, I.; Sanchez-Aponte, J.; Gonzalez-Delgado, A.; Jimenez, A.R.; Acevedo-Morantes, M. Removal and biodegradation of phenol by the freshwater Microalgae Chlorella vulgaris. Contemp. Eng. Sci. 2018, 11, 1961-1970. [CrossRef]

9. Ayed, L.; Bouguerra, A.; Charef, A.; Bakhrouf, A.; Mzoughi, R.E.L. Biodegradation of olive mill wastewater by a newly isolated novel bacterial consortium under RSM optimized culture conditions. J. Water Process Eng. 2019, 32, 100986. [CrossRef]

10. Sarris, D.; Stoforos, N.G.; Mallouchos, A.; Kookos, I.K.; Koutinas, A.A.; Aggelis, G.; Papanikolaou, S. Production of added-value metabolites by Yarrowia lipolytica growing in olive mill wastewater-based media under aseptic and non-aseptic conditions. Eng. Life Sci. 2017, 17, 695-709. [CrossRef]

11. Lopes, M.; Araújo, C.; Aguedo, M.; Gomes, N.; Gonçalves, C.; Teixeira, J.A.; Belo, I. The use of olive mill wastewater by wild type Yarrowia lipolytica Strains: Medium supplementation and surfactant presence effect. J. Chem. Technol. Biotechnol. 2009, 84, 533-537. [CrossRef]

12. Dourou, M.; Kancelista, A.; Juszczyk, P.; Sarris, D.; Bellou, S.; Triantaphyllidou, I.-E.; Rywinska, A.; Papanikolaou, S.; Aggelis, G. Bioconversion of olive mill wastewater into high-added value products. J. Clean. Prod. 2016, 139, 957-969. [CrossRef]

13. Martinez-Garcia, G.; Williams, C.J.; Burgoyne, A.; Edyvean, R.G.J. TEC18 Aerobic Treatment of Alpechin by Candida tropicalis. Expoliva-Foro la Tecnol. Oleícola y la Calid; The University of Sheffield: Sheffield, UK, 2015.

14. Arous, F.; Azabou, S.; Jaouani, A.; Zouari-Mechichi, H.; Nasri, M.; Mechichi, T. Biosynthesis of single-cell biomass from olive mill wastewater by newly isolated yeasts. Environ. Sci. Pollut. Res. 2016, 23, 6783-6792. [CrossRef]

15. Giavasis, I.; Petrotos, K. Biovalorization of olive mill waste water for the production of single cell protein from Saccharomyces cerevisiae, Candida utilis and Pleurotus ostreatus. Br. Biotechnol. J. 2016, 11, 1-16. [CrossRef]

16. Miller, G.L. Use of dinitosalicylic acid reagent for determination of reducing sugar. Anal. Chem. 1959, 426-428. [CrossRef]

17. Lopes, M.; Miranda, S.M.; Alves, J.M.; Pereira, A.S.; Belo, I. Waste cooking oils as feedstock for lipase and lipid-rich biomass production. Eur. J. Lipid Sci. Technol. 2019, 121, 1-33. [CrossRef]

18. D'Annibale, A.; Sermanni, G.G.; Federici, F.; Petruccioli, M. Olive-mill wastewaters: A promising substrate for microbial lipase production. Bioresour. Technol. 2006, 97, 1828-1833. [CrossRef] [PubMed]

19. Gonçalves, C.; Lopes, M.; Ferreira, J.P.; Belo, I. Biological treatment of olive mill wastewater by non-conventional yeasts. Bioresour. Technol. 2009, 100, 3759-3763. [CrossRef]

20. Karimi, M.; Hassanshahian, M. Isolation and characterization of phenol degrading yeasts from wastewater in the coking plant of Zarand, Kerman. Braz. J. Microbiol. 2016, 47, 18-24. [CrossRef] [PubMed]

21. Vatsal, A.A.; Zinjarde, S.S.; RaviKumar, A. Phenol is the initial product formed during growth and degradation of bromobenzene by tropical marine yeast, Yarrowia lipolytica NCIM 3589 via an early dehalogenation step. Front. Microbiol. 2017, 8, 1-15. [CrossRef]

22. Galíndez-Mayer, J.; Ramón-Gallegos, J.; Ruiz-Ordaz, N.; Juárez-Ramírez, C.; Salmerón-Alcocer, A.; Poggi-Varaldo, H.M. Phenol and 4-chlorophenol biodegradation by yeast Candida tropicalis in a fluidized bed reactor. Biochem. Eng. J. 2008, 38, 147-157. [CrossRef]

23. Satish, K.; Neeraj; Viraj, K.M.; Santosh, K.K. Biodegradation of phenol by free and immobilized Candida tropicalis NPD1401. Afr. J. Biotechnol. 2018, 17, 57-64. [CrossRef]

24. Badr, A.; Abd, E.-D.; Aziz, E.; Abou, A.; Awad, E.-N.; Zaki, G.H. Reduction of olive oil mill waste water phenolic compounds and COD using Paecilomyces variotii. Trends Ind. Biotechnol. Res. 2015, 1, 1-9.

25. Theerachat, M.; Tanapong, P.; Chulalaksananukul, W. The Culture or Co-Culture of Candida rugosa and Yarrowia lipolytica Strain RM-4A, or Incubation with Their Crude Extracellular Lipase and Laccase Preparations, for the Biodegradation of Palm Oil Mill Wastewater. Int. Biodeterior. Biodegrad. 2017, 121, 11-18. [CrossRef]

26. Jarboui, R.; Baati, H.; Fetoui, F.; Gargouri, A.; Gharsallah, N.; Ammar, E. Yeast Performance in wastewater treatment: Case study of Rhodotorula mucilaginosa. Environ. Technol. 2012, 33, 951-960. [CrossRef] [PubMed]

27. Sarris, D.; Rapti, A.; Papafotis, N.; Koutinas, A.A.; Papanikolaou, S. Production of added-value chemical compounds through bioconversions of olive-mill wastewaters blended with crude glycerol by a Yarrowia lipolytica strain. Molecules 2019, $24,222$. [CrossRef] [PubMed]

28. Lanciotti, R.; Gianotti, A.; Baldi, D.; Angrisani, R.; Suzzi, G.; Mastrocola, D.; Guerzoni, M.E. Use of Yarrowia lipolytica strains for the treatment of olive mill wastewater. Bioresour. Technol. 2005, 96, 317-322. [CrossRef] [PubMed]

29. Fadil, K.; Chahlaoui, A.; Ouahbi, A.; Zaid, A.; Borja, R. Aerobic biodegradation and detoxification of wastewaters from the olive oil industry. Int. Biodeterior. Biodegrad. 2003, 51, 37-41. [CrossRef] 
30. Mouncif, M.; Faid, M.; Achkari-Begdouri, A.; Lahdi, R. A biotechnological valorization and treatment of olive mill wastewaters by selected yeast strains. Grasas Y Aceites 1995, 46, 344-348. [CrossRef]

31. Ettayebi, K.; Errachidi, F.; Jamai, L.; Tahri-Jouti, M.A.; Sendide, K.; Ettayebi, M. Biodegradation of polyphenols with immobilized Candida tropicalis under metabolic induction. FEMS Microbiol. Lett. 2003, 223, 215-219. [CrossRef]

32. Gonçalves, F.A.G.; Colen, G.; Takahashi, J.A. Yarrowia lipolytica and its multiple applications in the biotechnological industry. Sci. World J. 2014, 2014, 1-14. [CrossRef]

33. Fickers, P.; Nicaud, J.M.; Destain, J.; Thonart, P. Overproduction of lipase by Yarrowia lipolytica mutants. Appl. Microbiol. Biotechnol. 2003, 63, 136-142. [CrossRef]

34. Fickers, P.; Nicaud, J.M.; Gaillardin, C.; Destain, J.; Thonart, P. Carbon and nitrogen sources modulate lipase production in the yeast Yarrowia lipolytica. J. Appl. Microbiol. 2004, 96, 742-749. [CrossRef]

35. Dey, P.; Maiti, M.K. Molecular characterization of a novel isolate of Candida tropicalis for enhanced lipid production. J. Appl. Microbiol. 2013, 114, 1357-1368. [CrossRef]

36. Lopes, M.; Gomes, A.S.; Silva, C.M.; Belo, I. Microbial lipids and added value metabolites production by Yarrowia lipolytica from pork lard. J. Biotechnol. 2018, 265, 76-85. [CrossRef] [PubMed]

37. Papanikolaou, S.; Chevalot, I.; Galiotou-Panayotou, M.; Komaitis, M.; Marc, I.; Aggelis, G. Industrial derivative of tallow: A promising renewable substrate for microbial lipid, single-cell protein and lipase production by Yarrowia lipolytica. Electron. J. Biotechnol. 2007, 10, 425-435. [CrossRef]

38. Radha, P.; Prabhu, K.; Jayakumar, A.; AbilashKarthik, S.; Ramani, K. Biochemical and kinetic evaluation of lipase and biosurfactant assisted ex novo synthesis of microbial oil for biodiesel production by Yarrowia lipolytica utilizing chicken tallow. Process Biochem. 2020, 95, 17-29. [CrossRef]

39. Donot, F.; Fontana, A.; Baccou, J.C.; Strub, C.; Schorr-Galindo, S. Single Cell Oils (SCOs) from oleaginous yeasts and moulds: Production and genetics. Biomass Bioenerg. 2014, 68, 135-150. [CrossRef]

40. Shields-Menard, S.A.; Amirsadeghi, M.; French, W.T.; Boopathy, R. A review on microbial lipids as a potential biofuel. Bioresour. Technol. 2018, 259, 451-460. [CrossRef]

41. Huang, C.; Luo, M.T.; Chen, X.F.; Qi, G.X.; Xiong, L.; Lin, X.Q.; Wang, C.; Li, H.L.; Chen, X.D. Combined 'de novo' and 'ex novo' lipid fermentation in a mix-medium of corncob acid hydrolysate and soybean oil by Trichosporon dermatis. Biotechnol. Biofuels 2017, 10, 1-11. [CrossRef]

42. Lopes, M.; Gomes, N.; Gonçalves, C.; Coelho, M.A.Z.; Mota, M.; Belo, I. Yarrowia lipolytica lipase production enhanced by increased air pressure. Lett. Appl. Microbiol. 2008, 46, 255-260. [CrossRef]

43. Koubeissi, H.; Yusef, H.; Holail, H. Evaluation of nutritional and environmental conditions for phenol degradation by a lebanese strain of Candida tropicalis. Int. J. Curr. Microbiol. Appl. Sci. 2017, 6, 1386-1398. [CrossRef]

44. Peng, R.; Hong, B.; Zhou, P. Screening and Production Optimization of a New Organic Solvent-Tolerance Fungal Lipase. In Proceedings of the International Conference on Biomedical and Biological Engineering, Shanghai, China, 15-17 July 2016; Atlantis Press: Amsterdam, The Netherlands, 2016; pp. 194-201.

45. Karakaya, A.; Laleli, Y.; Takaç, S. Development of process conditions for biodegradation of raw olive mill wastewater by Rhodotorula glutinis. Int. Biodeterior. Biodegrad. 2012, 75, 75-82. [CrossRef]

46. Alonso, F.O.M.; Oliveira, E.B.L.; Dellamora-Ortiz, G.M.; Pereira-Meirelles, F.V. Improvement of lipase production at different stirring speeds and oxygen levels. Braz. J. Chem. Eng. 2005, 22, 9-18. [CrossRef]

47. Kuttiraja, M.; Dhouha, A.; Tyagi, R.D. Harnessing the effect of PH on lipid production in batch cultures of Yarrowia lipolytica SKY7. Appl. Biochem. Biotechnol. 2018, 184, 1332-1346. [CrossRef] [PubMed]

48. Karatay, S.E.; Dönmez, G. Improving the lipid accumulation properties of the yeast cells for biodiesel production using molasses Bioresour. Technol. 2010, 101, 7988-7990. [CrossRef] [PubMed]

49. Darvishi, F.; Salmani, N.; Hosseini, B. Biovalorization of vegetable oil refinery wastewater into value-added compounds by Yarrowia lipolytica. J. Chem. Technol. Biotechnol. 2019, 94, 2961-2968. [CrossRef]

50. Lopes, M.; Belo, I.; Mota, M. Over-pressurized bioreactors: Application to microbial cell cultures. Biotechnol. Prog. 2014, 30, 767-775. [CrossRef]

51. Bellou, S.; Makri, A.; Triantaphyllidou, I.E.; Papanikolaou, S.; Aggelis, G. Morphological and metabolic shifts of Yarrowia lipolytica induced by alteration of the dissolved oxygen concentration in the growth environment. Microbiology 2014, 160, 807-817. [CrossRef]

52. Coelho, M.A.Z.; Amaral, P.F.F.; Belo, I. Yarrowia lipolytica: An industrial workhorse. Appl. Microbiol. Microb. Biotechnol. 2010, 930-944. Available online: http:/ / repositorium.sdum.uminho.pt/bitstream/1822/16867/1/3531.pdf (accessed on 20 December 2020).

53. Kumar, L.R.; Kaur, R.; Yellapu, S.K.; Zhang, X.; Tyagi, R.D. Biodiesel production from oleaginous microorganisms with wastes as raw materials. In Biofuels: Alternative Feedstocks and Conversion Processes for the Production of Liquid and Gaseous Biofuels; Elsevier Inc.: Amsterdam, The Netherlands, 2019; pp. 661-690.

54. Rakicka, M.; Lazar, Z.; Dulermo, T.; Fickers, P.; Nicaud, J.M. Lipid production by the oleaginous yeast Yarrowia lipolytica using industrial by-products under different culture conditions. Biotechnol. Biofuels 2015, 8, 1-10. [CrossRef]

55. Calvey, C.H.; Su, Y.K.; Willis, L.B.; McGee, M.; Jeffries, T.W. Nitrogen limitation, oxygen limitation, and lipid accumulation in Lipomyces starkeyi. Bioresour. Technol. 2016, 200, 780-788. [CrossRef] 
56. Liu, Z.J.; Liu, L.P.; Wen, P.; Li, N.; Zong, M.H.; Wu, H. Effects of acetic acid and ph on the growth and lipid accumulation of the oleaginous yeast Trichosporon fermentans. BioResources 2015, 10, 4152-4166. [CrossRef]

57. Ghaly, A.E.; Dave, D.; Brooks, M.S.; Budge, S. Production of biodiesel by enzymatic transesterification: Review. Am. J. Biochem. Biotechnol. 2010, 6, 54-76. [CrossRef]

58. Lopes, M.; Miranda, S.M.; Belo, I. Microbial valorization of waste cooking oils for valuable compounds production-a review. Crit. Rev. Environ. Sci. Technol. 2020, 50, 2583-2616. [CrossRef]

59. Yellapu, S.K.; Bharti; Kaur, R.; Kumar, L.R.; Tiwari, B.; Zhang, X.; Tyagi, R.D. Recent developments of downstream processing for microbial lipids and conversion to biodiesel. Bioresour. Technol. 2018, 256, 515-528. [CrossRef] [PubMed] 